\title{
Temporary Shelter-In-Place as Protection Against a Release of Airborne Hazardous Material: Report of a Literature Search
}

\author{
Report prepared by the \\ Decision and Information Sciences Division \\ Argonne National Laboratory \\ Report prepared for the \\ Federal Emergency Management Agency \\ Preparedness, Training and Exercises Directorate
}

March 16, 2001

Argonne National Laboratory, with facilities in the states of Illinois and Idaho, is owned by the United States Government and operated by The University of Chicago under the provisions of a contract with the Department of Energy. 


\section{Disclaimer}

This report was prepared as an account of work sponsored by an agency of the United States Government. Neither the United States Government nor any agency thereof, nor The University of Chicago, nor any of their employees or officers, makes any warranty, express or implied, or assumes any legal liability or responsibility for the accuracy, completeness, or usefulness of any information, apparatus, product, or process disclosed, or represents that its use would not infringe privately owned rights. Reference herein to any specific commercial product, process, or service by trade name, trademark, manufacturer, or otherwise, does not necessarily constitute or imply its endorsement, recommendation, or favoring by the United States Government or any agency thereof. The views and opinions of document authors expressed herein do not necessarily state or reflect those of the United States Government or any agency thereof, Argonne National Laboratory, or the University of Chicago. 


\section{CONTENTS}

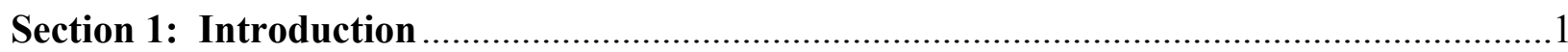

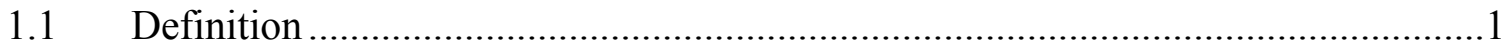

$1.2 \quad$ Purpose

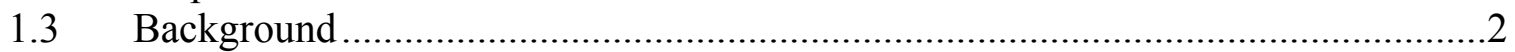

1.4 Scope of the Literature Search ............................................................................

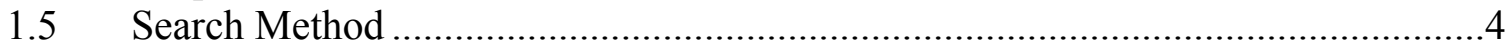

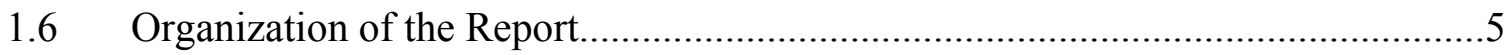

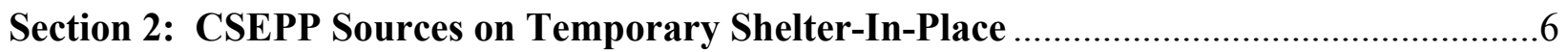

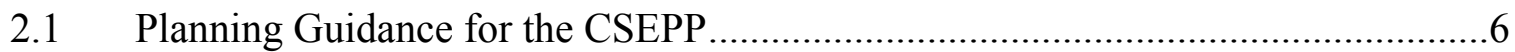

2.2 Oak Ridge National Laboratory Report ORNL-6615 ..........................................

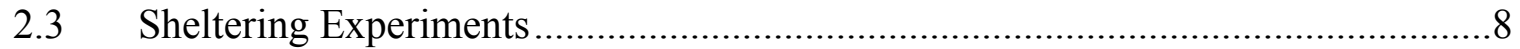

2.4 Toxicity and Toxic Effects of Chemical Warfare Agents .......................................

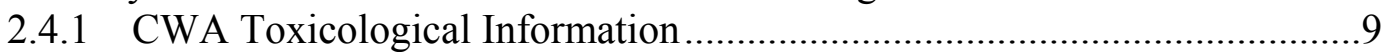

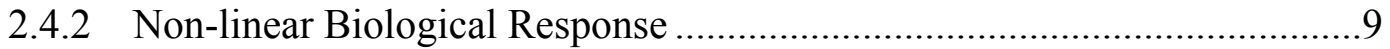

2.5 Site-Specific Concept Plans and Emergency Planning Guides .............................10

2.6 Plans, Procedures, and Agreements .................................................................

2.7 Training and Instruction for Hazard Analysts and CSEPP Planners ……..............12

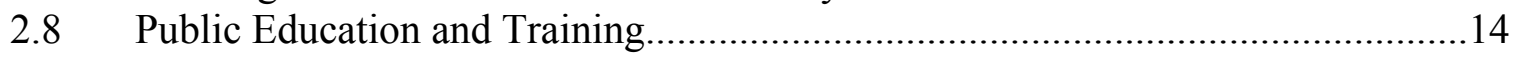

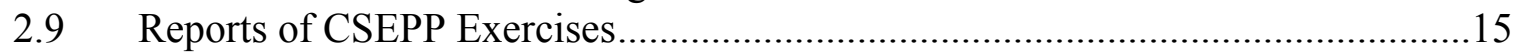

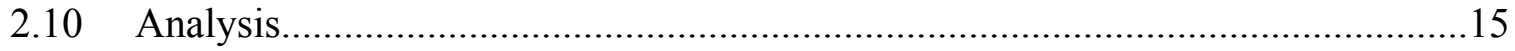

Section 3: CSEPP Modeling and Monitoring in Support of

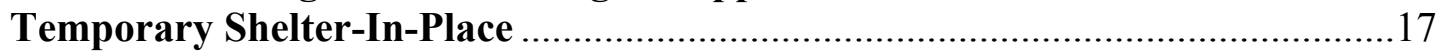

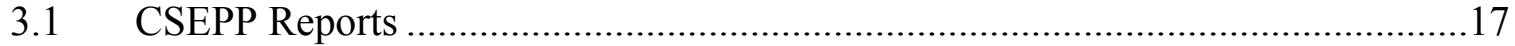

3.2 Army Plans and Procedures ............................................................................ 18

3.3 Training and Instruction for Hazard Analysts and CSEPP Planners .....................20

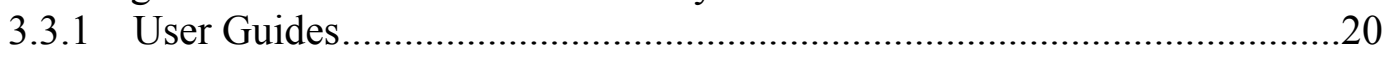

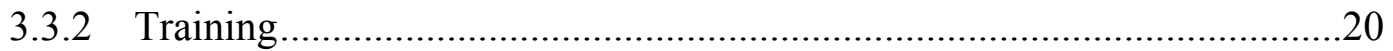

3.4 General Guidance on When to Exit from Shelters..............................................21

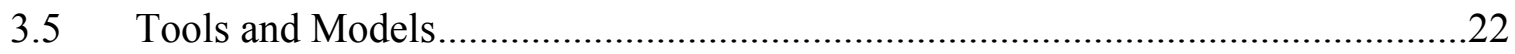

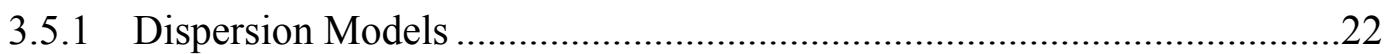

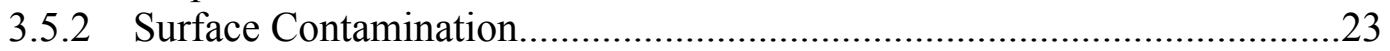

3.5.3 PAECE and PADRE Computer Models ………….................................24

3.5.4 Alabama CSEPP Protective Action Recommendation Guidebook ............25

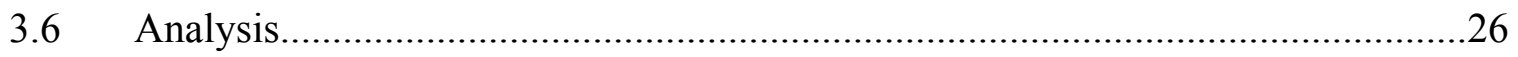

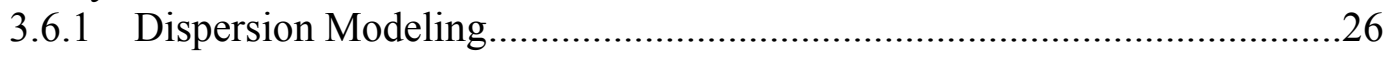

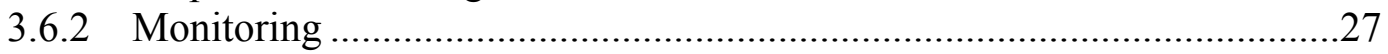




\section{CONTENTS Cont'd}

Section 4: Guidance From Other Programs on Temporary Shelter-In-Place

4.1 Existing Authorities .29

4.1.1 North American Emergency Response Guidebook ................................29

4.1.2 Criteria for Preparation and Evaluation of Radiological Emergency Response Plans and Preparedness in Support of Nuclear Power Plants

4.1.3 Manual of Protective Action Guides and Protective Actions for Nuclear Incidents .............................................31

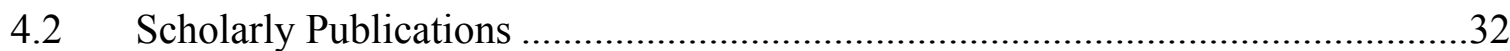

4.2.1 Indoor Air Quality and HVAC Systems ...............................................32

4.2.2 Proceedings of the Conference on In-Place Protection During Chemical Emergencies (1988).................................................32

4.2.3 Proceedings from Protecting the Public: A Conference on Protective Actions During Chemical Emergencies (1995)

4.2.4 Proceedings from Protecting the Public: A Conference on Protective Actions During Chemical Emergencies (1999) .......................35

4.2.5 Papers by Dr. David J. Wilson............................................................36

4.2.6 Shelter-In-Place: Planning and Implementation .....................................38

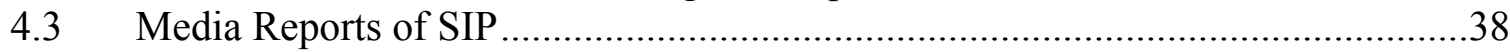

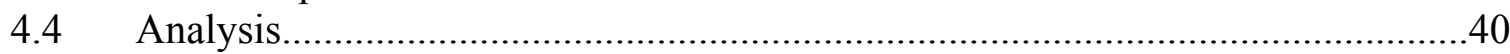

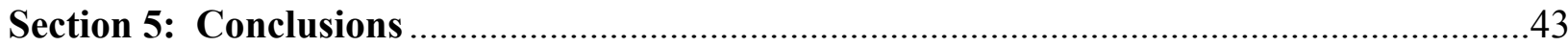

5.1 No "Off-the Shelf" Methods Available to Terminate SIP ...................................43

5.2 Possible Components of Methods to Terminate SIP ..........................................43

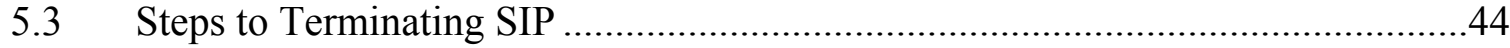

5.4 Task 2 Work on Methods to Decide When and How to Terminate SIP...............45

5.4.1 Reasons Why a Population Would SIP..................................................46

5.4.2 Choice of Tools to Use to Decide When and How to Terminate SIP ......................................................................48

5.4.3 Options Upon Termination of SIP ................................................48

Appendix 1: Potential for Buildup of Hazardous Vapors in Shelters During the Passage of a Plume of Airborne Hazardous Material ............................ A $1-1$

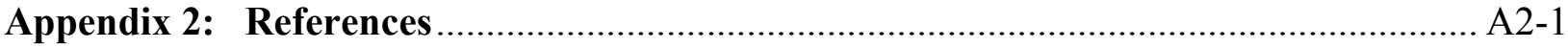

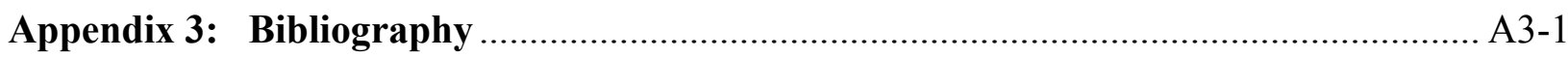

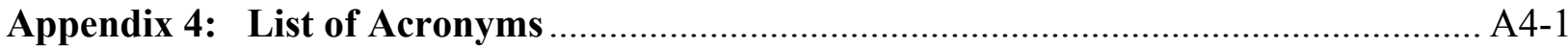




\title{
Temporary Shelter-In-Place as Protection Against a Release of Airborne Hazardous Material: Report of a Literature Search
}

by

\author{
George D. Yantosik, Ken Lerner, and Daniel M. Maloney
}

SECTION 1: INTRODUCTION

\subsection{DEFINITION}

"Temporary shelter-in place" is the combination of prompt shelter-in-place (SIP) to minimize initial exposure to airborne hazardous material, followed by timely action to terminate this protection to minimize exposure to hazardous vapor accumulations in the shelter once the air outside becomes less hazardous than the air inside the shelter. ${ }^{1}$

\subsection{PURPOSE}

Temporary SIP, if properly executed, is considered to be an effective way to protect populations from hazardous chemical vapors, especially from high concentrations for short periods. This is supported by laboratory and field experiments. The need for timely termination of temporary SIP as protection from infiltrated vapors is an integral component of a temporary SIP strategy. It was from this premise that Argonne National Laboratory (ANL) was asked to develop methodologies for deciding when and how to terminate SIP. These methodologies, in turn, could be the basis for site-specific operational guidelines (e.g., decision matrix, decision-tree, or algorithm) for terminating SIP on each of the eight Army chemical stockpile storage sites, and in the off-post communities surrounding them.

This project consists of two tasks. Task 1 was to collect and analyze existing literature that might be relevant to the termination of temporary SIP. This report is the product of Task 1. Task 2, which will begin on 2 February 2001, will use the results of the literature search as the baseline to investigate the concepts associated with temporary SIP, and to develop methodologies for termination of temporary SIP that can be incorporated in site-specific operational guidelines. It is understood that these methods will be consistent with Chemical Stockpile Emergency Preparedness Program (CSEPP) policy that "the most important objective of the emergency preparedness and implementation process is the avoidance of fatalities to the maximum extent practicable,

\footnotetext{
${ }^{1}$ The timely action could range from ventilating the shelter while it is still occupied, exiting to the exterior during the shelter ventilation period, or relocating immediately to a safe location. This action is essential because hazardous vapors infiltrate the shelter during the passage of the plume, unless the shelter air is filtered and maintained at a positive pressure with respect to outside air.
} 
should an accidental release of chemical agent occur." ${ }^{2}$ It is also anticipated that these methods will be consistent with approved dispersion models and compatible with the approved emergency management information systems and alert and notification protocols.

\subsection{BACKGROUND}

As the CSEPP at the eight Army chemical stockpile storage sites in the continental United States has matured, temporary SIP to protect the population on and around these sites has become more attractive as a complement or alternative to immediate evacuation.

A major challenge facing emergency managers and protective action decision makers is the limited guidance available about when and how to terminate temporary SIP, to ensure the proper application of this protective action strategy. Long-standing CSEPP guidance expresses concern for exposure of sheltered persons to infiltrating hazardous vapors. ${ }^{3}$ See Appendix 1 of this report for information about the potential for buildup of hazardous vapors in shelters during the passage of a plume of airborne hazardous material. ${ }^{4}$ Some Army and local emergency response plans also discuss concern over agent infiltration in shelters but do not describe methods to cope with this problem. ${ }^{5}$ State and local emergency response plans generally expect that decisions regarding the termination of SIP off-post will be based on Army protective action recommendations (PARs). However, while Army hazard analysts are very capable of developing initial PARs that include immediate sheltering as an option, Army guidance does not specify criteria for making a defensible recommendation for terminating temporary SIP. This also impacts decisions by off-post officials who lack guidance on how to implement this part of the temporary SIP strategy unilaterally, in the absence of Army PARs.

Dispersion modeling is the primary tool that hazard analysts use following an accidental release of chemical agent from an Army chemical stockpile site. Currently, D2PC with PARDOS are the approved dispersion models that are integrated into EMIS/FEMIS for use at all sites. The D2-Puff model has also been accredited for use but is not yet integrated into EMIS/FEMIS. D2-Puff is only available at three of the eight storage installations as of the date of this report, and only as a stand-alone system. These sites have not yet developed protocols with off-post emergency managers to use D2-Puff. Eventually D2-Puff could be employed for hazard analysis after the initial PARs and

\footnotetext{
${ }^{2}$ CSEPP Policy Paper Number 1.

3 "The duration of protection offered by unpressurized shelters is limited. Because such shelters cannot be made completely air-tight, they will be gradually infiltrated by chemical agent. ... Consequently, unpressurized shelters should be used only for .... releases whose duration is shorter than .... the time it would take agent to infiltrate .... In addition, use of unpressurized shelters requires the capability to advise sheltered people to abandon their shelters when the plume has passed." (See CSEPP 1996, p. 8-16)

${ }^{4}$ For the purposes of this report, SIP refers only to non-pressurized (normal, expedient, and enhanced) shelters, since pressurized shelters are not subject to hazardous vapor infiltration. (CSEPP 1996, p. 8-16).

5 For example, the ANAD CAIRA Plan says only that persons sheltered on-post should "remain in place until you are told that it is safe to leave" (Anniston Army Depot [ANAD] 1999, Annex G).
} 
PADs have been made, and could help the Army update the initial on-post PADs and offpost PARs.

D2PC with PARDOS provides estimates of when the leading and trailing edges of a chemical agent plume will reach specified populated or occupied areas. The plume's direction of travel and estimated arrival time can be used to determine which protective actions (e.g., immediate evacuation or temporary SIP) should be completed for specific jurisdictions or areas to minimize exposure of the public to chemical agent. Estimates of the plume departure time can also provide a basis for determining when persons should ventilate and/or exit the shelter and then possibly relocate.

Unfortunately, the predicted plume departure time is only valid when the model calculations are based on representative meteorological data and the actual source term parameters for the chemical agent released. Many of the hazard assessments that might be made in the event of an actual emergency (especially the initial assessment) are based on the work plan maximum credible event (MCE) because of the likelihood of many unknowns immediately following an accidental release. These assumptions can be inaccurate compared to what actually happened. ${ }^{6}$ Similarly, the actual properties of the plume (e.g., concentrations, duration of release, and tip and tail times) can be significantly different from predictions made by using the MCE. Therefore, some PARs and protective action decisions (PADs) based on these hazard assessments can significantly overestimate or underestimate plume departure times-potentially important criteria for decisions about temporary SIP.

Chemical events that might occur other than during chemical operations are much less likely, though they can be catastrophic (e.g., a fire in a chemical agent storage structure). These catastrophic events are expected to be self-evident, with potentially high concentrations of agent vapors released over a significant period of time.

Additionally, the guidance available about temporary SIP does not always differentiate among the types of temporary shelters that might be used, i.e., normal, expedient, enhanced, and collective protection/pressurized, and how these variables constrain options for temporary SIP.

The Federal Emergency Management Agency (FEMA) and the Army believe that issues associated with temporary SIP should be studied, that methodologies should be outlined for deciding when and how to terminate temporary SIP, and that site-specific operational guidelines to implement these methodologies should be developed. This

\footnotetext{
${ }^{6}$ The MCE is the worst single event that could occur at any time with maximal release of chemical agent from a munition, bulk container, or process as a result of an unintended, unplanned, or accidental occurrence. The event must be realistic with a reasonable probability of occurrence. (See DA Pam 50-6, p 110.) A work plan MCE is a hazard prediction made by Army hazard analysts prior to commencing operations at a work site involving chemical agents or munitions. This information is analyzed on-post to ensure first responders are prepared to react to the MCE at the work site. The work plan MCE is also shared with off-post emergency management officials so they can respond more quickly if an accident should occur at the work site.
} 
information will help make planning for temporary SIP PARs and PADs, and associated requests for necessary resources, more effective and defensible.

\subsection{SCOPE OF THE LITERATURE SEARCH}

The literature search conducted by ANL included review of professional publications, technical reports, emergency response plans, case studies, news articles, accident reports, training programs, Army and CSEPP program guidance, emergency response exercise reports, and emergency management agency policies. These materials were reviewed for information, lessons learned, and protocols. The search was organized to capture information about termination of temporary SIP from three major sources:

- CSEPP-sponsored policies and publications, Army and civilian emergency response plans, agreements at and around Army chemical stockpile storage sites, and reports of CSEPP exercises.

- Publications giving descriptions and instructions on modeling and monitoring that have the potential to support and defend methodologies to terminate temporary SIP.

- Publications by government agencies, professional organizations, and industry sources discussing concepts, methods, and experiences applicable to temporary SIP to protect against any airborne hazardous material. The search also included newspaper articles about hazardous materials (HAZMAT) accidents when sheltering was used to protect populations.

\subsection{SEARCH METHOD}

Information was gathered from files at ANL, the U.S. Army Soldier and Biological/Chemical Command (SBCCOM), Army chemical storage sites, and by direct solicitation from other sources. The search included library catalogs, journal summaries, the Internet, and electronic news-clipping services. Some pertinent references were found by examining the reference lists and bibliographies of primary documents reviewed early in the search. This approach ensured a comprehensive search for information about termination of temporary SIP. More than 1,000 documents were selected for review on the basis of their titles and general subject matter. Of these, only about $10 \%$ contained what appeared to be useful information.

There was much duplication of information among the many documents that were reviewed. In order to reduce redundancy, and to keep this report to a manageable size, some references that did not add to the information about terminating SIP that was already covered were not cited in this report. 


\subsection{ORGANIZATION OF THE REPORT}

The body of this report is divided into three main sections, corresponding to the types of sources described in section 1.4 above.

- CSEPP Sources on Temporary Shelter-in-Place (Section 2). This section discusses the existing guidance, concepts, and methods that apply to using temporary SIP on and around Army chemical stockpile storage sites to protect against exposure to nerve and blister agents. The results of the search for information about modeling and monitoring are covered separately, in Section 3.

- Modeling and Monitoring in Support of Temporary Shelter-in-Place (Section 3). This section discusses the use of modeling and monitoring to support decisions to terminate temporary SIP.

- Guidance From Other Programs on Temporary Shelter-in-Place (Section 4). This section discusses concepts, methods, and experiences using temporary SIP elsewhere to protect against any airborne hazardous material.

Documents cited directly in this report are listed in Appendix 2 and a bibliography listing the major documents considered during this search is given in Appendix 3. Acronyms used in the report are listed in Appendix 4. 


\section{SECTION 2: CSEPP SOURCES ON TEMPORARY SHELTER-IN-PLACE}

The literature search discussed in this section was guided in part by the desire to answer the following questions:

- What does Army and CSEPP guidance and policy say about terminating temporary SIP?

- What concepts, policies, plans, methods, or procedures pertaining to terminating temporary SIP have been implemented at Army chemical stockpile storage sites?

- What concepts, policies, plans, methods, or procedures pertaining to terminating temporary SIP have been implemented in communities adjacent to Army chemical stockpile storage sites?

\subsection{Planning Guidance for the CSEPP}

The document Planning Guidance for the CSEPP calls for immediate initial PARs and PADs (within minutes of the detection of a chemical accident), with subsequent immediate alert and notification of the populations at risk (CSEPP 1996, pp. 8-13, F-4, F-5, F-9 and F-10). The general guidance also requires the update of PARs and PADs when circumstances change or when notification instructions to the public need to be expanded, but does not discuss the methods to decide when and how to terminate temporary SIP. The update of PADs is an important consideration, because alert and notification processes are expected to "continue at regular intervals, initiated at least every 12 minutes for the first hour and every 20 minutes thereafter, until the danger to the public is determined to be past." (CSEPP 1996, p. F-10) Therefore, a change in the PAD to terminate SIP needs to be reflected in changes to the regular alert and notification broadcasts in time for the affected population to respond appropriately.

Protective action decision-making for chemical stockpile emergencies is discussed in Chapters 7 and 8 of Planning Guidance for the CSEPP. The guidance emphasizes that evacuation is the preferred protective action if it can be accomplished prior to arrival of the agent hazard. It acknowledges, however, that SIP may be preferable in close-in areas under circumstances where time does not permit evacuation before the arrival of the agent hazard. (p. D-4). Furthermore, the guidance acknowledges that:

"... some chemical emergency scenarios require making decisions for the IRZ [immediate response zone] in less than ideal circumstances. These constraints may require that some jurisdictions plan for more automatic decision making. Automatic responses such as taking shelter at once, sealing a room, etc., may be needed" (p. 7-2).

The most detailed treatment of protective action decision making in the CSEPP planning guidance occurs in Appendix D. It advises that: 
"Shelter feasibility is determined by the infiltration rate into the structure and the duration that the structure is in the plume. In general, sheltering is not a good protective action when the accident is of a long duration or if the structure has a high infiltration rate. Moreover, people must vacate or air out the shelter when the plume has passed in order to minimize exposure to chemical vapors that entered the shelter while it was in the plume" (p. D-4).

According to Appendix D, these considerations should be taken into account by planners, along with input from hazard analyses and other information, in constructing a decision matrix that maps accident conditions to protective action recommendations. The decision matrix would link a given set of releases and meteorological conditions to a set of protective actions for the various population groups (e.g., general public, schools, and institutions) in particular preset zones. Public officials could use this matrix to quickly reach decisions in an emergency without time-consuming analysis or weighing of competing factors. ${ }^{7}$

Other than recommending that this planning and coordinating process be performed ahead of time, however, Appendix D does not advise on how to link particular release scenarios or duration estimates to particular protective actions. In particular, it does not directly address the issue of determining when to evacuate or ventilate following a shelter-in-place instruction other than to do so after the plume has passed.

It also seems logical that decisions about ventilating or exiting from shelters, or relocating from temporary shelters to a known safe location, though made deliberately, should be implemented with the same urgency as the initial PARs, PADs, and public notification instructions. This logic is supported by Objective 5, Evaluation Element 5.1, in the CSEPP Exercises program guide (CSEPP 1999a, p. 5.1-2). ${ }^{8}$

\subsection{Oak Ridge National Laboratory Report ORNL-6615}

The Oak Ridge National Laboratory Report ORNL-6615, Evaluating Protective Actions for Chemical Agent Emergencies, was among the earliest and most widely referenced documents that discussed SIP. (Rogers et al.1990). It notes that the air infiltration rate will vary for a given shelter based upon a number of parameters such as the wind speed, wind direction, temperature, and the numbers of doors and windows open. Four shelter types are typically considered in CSEPP: normal, enhanced, expedient, and pressurized. This report describes these shelters as follows:

\footnotetext{
${ }^{7}$ According to CSEPP 1996, p. D-7, the planning for emergency decision-making should be in the form of a decision table as in the example in Figure 2.3 in Appendix N, p. N-2-8.

${ }^{8}$ Debate about the obligation of the Army to make an updated PAR when the Army hazard analyses shows that the original PAR has been overtaken by events is a policy matter outside the scope of this report. That policy could impact the methods available to implement a successful temporary shelter strategy.
} 
"Pressurized shelters are characterized as a special case where there is no exchange of air from the unprotected to the protected environment $(0.0$ $\mathrm{ACH}$ [air changes per hour]). Enhanced shelters are weatherized structures where the air exchange between interior and exterior environments is reduced. Because these structures are weatherized in advance of the accidental release of chemicals, they can be assumed to have low exchange rates $(0.5 \mathrm{ACH})$ and require only that doors and windows be closed to achieve the desired level of protection. Expedient shelters can achieve further reductions in air exchange (represented here as $0.2 \mathrm{ACH}$ ) but require more time to implement procedures to achieve the maximum protection" (p. xxvii).

The procedures required for a shelter to be classified as an expedient shelter require that the occupants go to an interior room, close the door, and seal off the room with tape and plastic - after the release has occurred. The baseline, normal shelter, is a leaky building that has not been weatherized. The ORNL report lists an air exchange rate of $1.5 \mathrm{ACH}$ for this type of shelter. Summarizing, the following shelter types will have the following approximate air infiltration rates:

- Normal (typical leaky shelter): $1.5 \mathrm{ACH}$

- Enhanced (weatherized shelter): $0.5 \mathrm{ACH}$

- Expedient (modifications at time of accident: occupants seal an interior room): $0.2 \mathrm{ACH}$

- Pressurized (only filtered air exchanged with outside environment): $0 \mathrm{ACH}$

Other information in this reference that might be useful during work on Task 2 include plume dispersion, decisions to warn, the warning process, public response to emergency warnings, and warning compliance.

\subsection{SHELTERING EXPERIMENTS}

Filtration and sorption of chemical warfare agents (CWAs) are two notable mechanisms by which people who shelter in place might be additionally protected. Blewett and Arca (1999) studied the effectiveness of filtering in protecting against sarin and mustard vapor. This study, based upon experimentation, reports that building materials, furnishings, carpets, drapes, and so forth might provide an increased protection factor of between 15 and 50 for mustard gas and between 2 and 3 for sarin. ${ }^{9}$ Subsequent studies (Test Report for the System Effectiveness Test of Home/Commercial Portable Room Air Cleaners, April 2000; and IEM Alabama Analysis, not yet complete) have investigated the additional protective capability from using portable carbon recirculation filter units. This protection is in addition to the protection provided by the shelter

\footnotetext{
9 "Protection factor" is defined here as the ratio of the toxic dosage that would be received without protection divided by the toxic dosage that would be received with protection.
} 
structure. It is important to note that the protection factors were assessed assuming a linear biological response to the CWA, and therefore these protection factors might need to be reevaluated to consider the latest information about the toxicology of certain CWAs.

\subsection{TOXICITY AND TOXIC EFFECTS OF CHEMICAL WARFARE AGENTS}

\subsubsection{CWA Toxicological Information}

According to Myirski 2000, the Environmental Protection Agency (EPA) is considering the approval of toxicological information for nerve and mustard agents that define their toxic effects more accurately. The toxicological information is based upon the findings of the National Advisory Committee to Develop Acute Exposure Guideline Levels (AEGLs). ${ }^{10}$ The AEGLs are recommended upper limits for exposure to the general public, based on emergency exposure periods ranging from less than 1 hour up to 8 hours. This CWA toxicological information represents the toxicological effect of nerve agents to be non-linear. The toxicological information for mustard gas is now given as non-linear for a short exposure time (i.e., 10 minutes), but remains linear at longer exposure times.

Using this proposed information, GB and HD are overall less toxic than they are assumed to be in current CSEPP documentation and models (e.g., as used in D2PC), while VX is significantly more toxic. The proposed AEGLs for the CWA will be provided for set exposure periods (i.e., AEGL values for 10-minute, 30-minute, 1-hour, 4-hour, and 8-hour exposures). The Army plans to replace the 1\% Lethality dosage with the AEGL-3 value and the No Effects dosage with the AEGL-2 value (Myirski 2000).

\subsubsection{Non-linear Biological Response}

As noted above, the AEGL toxicological information will be provided for set exposure periods. While these exposure periods will directly account for the non-linearity of the toxic effect of CWA, the following provides background to explain the issue of

10 The three AEGLs have been defined as follows (U.S. Environmental Protection Agency National Advisory Committee 2000, verbatim):

AEGL-1 is the airborne concentration (expressed as ppm or $\mathrm{mg} / \mathrm{m}^{3}$ ) of a substance at or above which it is predicted that the general population, including "susceptible" but excluding "hyper-susceptible" individuals, could experience notable discomfort. Airborne concentrations below AEGL-1 represent exposure levels that could produce mild odor, taste, or other sensory irritations.

AEGL-2 is the airborne concentration (expressed as $\mathrm{ppm}$ or $\mathrm{mg} / \mathrm{m}^{3}$ ) of a substance at or above which it is predicted that the general population, including "susceptible" but excluding "hyper-susceptible" individuals, could experience irreversible or other serious, long-lasting effects or impaired ability to escape. Airborne concentrations below the AEGL-2 but at or above AEGL-1 represent exposure levels that may cause notable discomfort.

AEGL-3 is the airborne concentration (expressed as ppm or $\mathrm{mg} / \mathrm{m}^{3}$ ) of a substance at or above which it is predicted that the general population, including "susceptible" but excluding "hyper-susceptible" individuals, could experience life-threatening effects or death. Airborne concentrations below AEGL-3 but at or above AEGL-2 represent exposure levels that may cause irreversible or other serious, longlasting effects or impaired ability to escape. 
non-linearity. A paper entitled "Influence of Non-Linear Human Response to Toxic Gases on the Protection Afforded by Sheltering-In-Place" (Wilson and Zelt 1990) provides further insight on how the proposed toxicological information for the CWA will impact toxic effect.

As outlined in this paper, Haber's Law can be used to determine the effect of concentration and exposure time for chemicals whose toxic effect is linear (i.e., cumulative dosage is important), such as from heavy metal and radiation exposure. For these cases, Haber's Law states that

$$
\text { toxic effect }(\text { or dosage })=(\text { concentration }) \times(\text { exposure time })
$$

For cases where the biological response to a chemical exposure is not linear, Wilson provides the following modification to Haber's Law to describe the toxic effect (or toxic load):

$$
\text { toxic effect }(\text { or toxic load })=(\text { concentration })^{\mathrm{n}} \times(\text { exposure time })
$$

In this case, the exponent $n$, which is a chemical-specific parameter, is a measure of the degree to which the toxic effect is related more to peak concentrations than to cumulative dosage. Note that the second equation can be used even when the biological response is linear by setting the value of $n$ to 1 . Increasing values of $n$ indicate that peak concentrations play an increasing role in toxic effect. Wilson notes that in most cases the exponent $n$ is between 1.5 and 3.5 .

In the derivation of the AEGLs for GB, for example, an $n$ value of 2 was used. The other nerve agents, which are also under various stages of review, have values of $n$ greater than 1. Thus, using the proposed GB toxicology for example, a doubling of the agent concentration would have the same toxic effect in one quarter of the time (i.e., higher concentrations for shorter times are worse than lower concentrations for proportionally longer times).

\subsection{SITE-SPECIFIC CONCEPT PLANS AND EMERGENCY PLANNING GUIDES}

To assist with implementation of CSEPP planning guidance at each stockpile site, site-specific Emergency Response Concept Plans were developed by Oak Ridge National Laboratory (ORNL) for each site. These are listed in the bibliography (Appendix 3). In addition, Emergency Planning Guides were prepared by ANL for four of the sites to update and supersede the Emergency Response Concept Plans at those sites. These are also listed in the bibliography. These documents provide data relevant for planning, as well as some site-specific analysis as to how the planning guidance should be applied. However, the samples reviewed did not provide specific advice on the timing or protocol for terminating temporary SIP. 
The literature search also considered a technical report done by SSI Services for the Kentucky CSEPP (SSI Services 1998). The report included a decision table (p. 13) that related accident categories with public protective action strategies. Of interest in this report was the list of assumptions that were agreed to as the basis for the protective action strategies. Some assumptions were:

- $\quad$ PADs will be made and communicated to the public by zone.

- All zones will be modeled using the point physically nearest the depot.

- An aggressive public information program, resulting in a rapid public response to warning messages, will be assumed.

- Only normal shelter-in-place will be used, excluding expedient, enhanced or pressurized shelters, even though the public education program will include expedient SIP information.

- All in-place protection will be followed by evacuation.

- People who receive an agent dosage equivalent to $30 \mathrm{mg}-\mathrm{min} / \mathrm{m} 3$ of GB will be too impaired to drive.

- The filtering effect of structures can significantly reduce sheltered dosages.

- Evacuation will occur without family reunion.

\subsection{PLANS, PROCEDURES, AND AGREEMENTS}

Chemical accident/incident response and assistance (CAIRA) plans and procedures at Army chemical storage sites do not include concepts and methods for temporary SIP to protect the post population. Most plans state that SIP for select populations on-post are a PAD option, but this option is mentioned only as an alternative to evacuation when evacuation is not feasible, without regard for the duration of the effectiveness of sheltering. There are no discussions of the limitations of SIP in terms of infiltration of agent vapors, nor plans to determine when these shelters should be ventilated or evacuated.

Similarly, none of the Army CAIRA plans and procedures provide for termination of temporary SIP as a PAR for the off-post population that might be at risk, though SIP is often mentioned as an alternative to evacuation. Plans and procedures do not address the limitations of SIP, nor do they discuss when and how to terminate this protection, though the Umatilla Chemical Depot CAIRA Plan (Umatilla Chemical Depot 2000), states: "If shelter-in-place is recommended, state and local authorities must be kept advised regarding plume passage, to assist them in their decision making process (evacuation after plume passage). Local and state elected officials are responsible for final protective 
action decisions." The absence of temporary SIP considerations in memoranda of agreement was also noted during the literature search.

The situation is similar in nearby communities. A survey by ANL staff of off-post plans and procedures showed frequent mention of SIP as an alternative to evacuation, but with little information about the actions needed to terminate this option effectively.

\subsection{TRAINING AND INSTRUCTION FOR HAZARD ANALYSTS AND CSEPP PLANNERS}

The fact that agent infiltrates normal, expedient, and enhanced shelters is nothing new, and much of the literature says that SIP is an appropriate temporary protection only under certain conditions, usually involving plumes of short duration. This information has been incorporated in training and instruction for hazard analysts and CSEPP planners for years.

The slides and handouts for the "Chemical Hazard Prediction for Decision Makers" course formerly taught by the U.S. Army Defense Ammunition Center (USADAC) illustrate this training and instructional effort. (This material is now incorporated in USADAC's new courses, "Chemical Emergency Information for Managers" and "Chemical Hazard Prediction.") (USADAC 1995, 1999a, b). One slide shows that sheltering is an option when "evacuation is not feasible," and results in "agent concentration greater in shelters after plume passage (except pressurized shelters)." The next slide states that "normal, expedient, and enhanced shelters DO NOT ELIMINATE dosages within shelters." Another slide addresses ventilation of shelters using PARDOS2 to predict plume tail time, a decision supplemented by monitoring if feasible. Yet another slide stresses the need to update the hazard assessment as new information becomes available, an issue relevant to updating PARs and PADs with information on when to ventilate or leave shelters, for example.

This course includes a sub-course on "Situation Analysis and Decision Making." A slide from this sub-course says "Many buildings can provide significant protection against chemical agent vapors, particularly in releases of short duration." This qualifies the utility of shelter-in-place and implies that shelter-in-place is a temporary measure. More to the point is a subsequent slide that says "The duration of protection offered by unpressurized shelters is limited and depends on the duration of the plume and the quantity of airborne agent (source strength). Because such shelters cannot be made completely air-tight, they will be gradually infiltrated by chemical agent entering around the door and window seals, ventilation openings, etc." Associated with this sub-course is a checklist that says when making PARs and PADs one must consider the potential duration of the plume for those sheltering in place. The essentials of this concept are also mentioned in the "Service Response Force Commander/On-Scene Coordinator" course taught periodically by USADAC. However, this literature search has not found evidence that the above information has been translated into temporary SIP concepts and procedures at and around the Army chemical stockpile storage sites. 
The "Technical Planning and Evaluation Course" prepared for the CSEPP by Oak Ridge National Laboratory (described in Copenhaver et al. 1995) also discussed agent infiltration in shelters and the importance of terminating SIP.

"People in the unpressurized shelters would be exposed to gradually increasing concentrations of agent. Thus exposure would continue even after the chemical agent plume has passed by outside, due to the time lag inherent to the infiltration process. Consequently, unpressurized shelters should be used only for chemical agent releases whose duration is shorter than the length of time that it would take agent to infiltrate the shelters. In addition, use of unpressurized shelters requires the capability to advise sheltered people to open up their shelters to allow fresh air to enter inside when the plume has passed." (Copenhaver et al. 1995, p. 32)

A presentation about Shelter-In-Place as a Protective Action From Inhalation Exposure (Sorensen et al. 1995) made the following points:

- SIP is effective at reducing peak concentration, and reducing cumulative exposure for limited duration (approximately 30 minutes for normal shelter and 1-3 hours for enhanced or expedient shelter.)

- SIP requires an aggressive public education effort to convince people to implement SIP and then to leave or ventilate shelter when recommended.

- Non-pressurized shelters require that local authorities have the capability to determine when the plume has passed a given area, and to notify shelter inhabitants to leave or ventilate.

- To best estimate the duration of plume passage, it is recommended that the affected communities work with the Army installation to rapidly communicate when the agent release has terminated and when the tail end of the plume has passed specific locations in the community.

The literature search also considered draft student manuals prepared by IEM, Inc, to train emergency management personnel at the civilian jurisdictions surrounding Umatilla Chemical Depot. These covered "Protective Action Implementation: Sheltering and Evacuation" and "Sounding All-Clear for Sheltered Personnel." The former manual (IEM 1999a) contrasts sheltering with evacuation, referring to the All-Clear training for terminating SIP. Section 2.7 in the latter manual (IEM 1999b) discussed two possible times for vacating shelters. First is an optimal time - when dosage outside the shelter drops below dosage inside the shelter, and second, when the trailing edge of the plume has passed beyond the shelter. The manual says that the complexity of the multiple factors involved, and the variation in shelter characteristics between buildings, precludes measuring or modeling the optimum time in real time. Leaving shelter too early is worse than leaving late. Therefore, issuing the All-Clear Warning at tail time is the most 
appropriate concept. This premise is supported by the capability to calculate the tail time with the D2PC model.

\subsection{PUBLIC EDUCATION AND TRAINING}

Planning Guidance for the CSEPP (CSEPP 1996, Appendices E and J) calls for an ambitious public education and training effort concerning the need to abandon shelters when advised to do so. This guidance makes sense, because a seamless emergency response plan with foolproof methods to alert and notify the public to implement a temporary SIP strategy counts for little if the public is not educated and trained to execute the strategy (p. E-3). However, few of the CSEPP public information programs, handouts, calendars, etc., examined during this literature search that mention SIP discussed why it is vital to ventilate or depart from temporary shelters promptly when instructed, perhaps very soon after taking shelter initially. ${ }^{11}$ The absence of temporary SIP materials in CSEPP public education and training programs was confirmed by Kay Ingle, who told literature searchers: "I can't recall any public information education materials that address the issue. I know that the PAOs [public affairs officers] and PIOs [public information officers] at some of the sites are becoming more aware of the need to leave a building and ventilate, so it may be in some of the newer materials now in draft." 12

During the literature search, ANL also inquired into the extent to which public education and training on termination of temporary SIP was reflected in the behavior of decision makers during CSEPP exercises or used to advantage by other players. In addition to reviewing all exercise reports from 1997 to the present, the authors of this report asked several controllers who played the roles of the media and the public in these exercises about how this issue was played during exercises. Their perspective was summarized by remarks from Kay Ingle, the lead controller in this area for dozens of exercises, who said:

"This has come up in exercises and the mock media has made inquiries of PAOs and PIOs along this line. The response is usually 'I'll have to get back to you on that.' Sometimes they actually do, after talking with their EOC [Emergency Operations Center]. Injects introduced from exercise simulation cells representing the concerns of citizens affected by the simulated accident get similar responses. I have been aware of this aspect of shelter-in-place since the first project I did for ANL in 1989, and have

\footnotetext{
${ }^{11}$ An informal survey of CSEPP public information materials indicated that most provide basic instructions on how to implement SIP, including a suggestion to bring a radio to listen to EAS for further instructions. Materials for two counties in Alabama (St. Clair and Cleburne) did directly address the issue of temporary shelter, saying that, "Once the danger has passed, you must leave your home when authorities tell you that it is time. You may be putting yourself in more danger by staying in your home rather than leaving. Your home will absorb some of the chemical vapor and must air out in order for it to be safe to inhabit." (St Clair County EMA undated). On the other hand, some materials did not even mention SIP in connection with CSEPP, describing evacuation procedures only.

${ }^{12}$ Kay Ingle is an ANL project manager who has worked extensively with CSEPP planners, PAOs, and PIOs. Quotes from Kay Ingle in this report were obtained on 4 December 2000.
} 
raised the issue in my training of PAOs and PIOs a few times with little reaction from the training participants. The public education emphasis has always been on trying to convince people that sheltering is a legitimate protective action, explaining what to do to accomplish same, and that it might be a better protective action option than evacuation in some circumstances. However, players seemed reluctant to admit that people who take shelter might be exposed to the infiltration of vapor hazards."

\subsection{REPORTS OF CSEPP EXERCISES}

Since the inception of the CSEPP exercise program, evacuation has been demonstrated as the PAR and PAD of choice both on-post and off-post. This reflects the wisdom that evacuation is the best protection if it can be accomplished safely and in time. SIP decisions were also made in many exercises, but the limitations of that protection with respect to vapor infiltration of shelters were rarely demonstrated, and never successfully, according to published reports of exercises. Only during 2000, as the difficulties with evacuation were becoming manifest, has SIP been looked at closely in CSEPP exercises as an attractive alternative to evacuation. ${ }^{13}$ During 2000, players in CSEPP Community Exercises at Pine Bluff, Umatilla, Newport, Deseret, and Blue Grass all incorporated temporary sheltering as a primary or priority alternate protection, but without demonstrating protection from the shelter infiltration problem during the timeline of the exercise. ${ }^{14}$ Some questions were raised about the efficacy of sheltering following each of these exercises, but these concerns were only documented in the Umatilla and Newport Community CSEPP Exercise reports (CSEPP 2000a, b).

\subsection{ANALYSIS}

Despite information and guidance discussed in this section that supports temporary SIP when appropriate, decision matrices for temporary SIP have not been constructed at each site, and implementing concepts and methods have not been developed. It is possible that extraordinary efforts over the years to perfect an immediate evacuation strategy were done at the expense of developing temporary SIP methodology. It is also possible that the search for a perfect solution to problems with temporary SIP kept CSEPP planners from developing the maximum protection that can be achieved with obtainable capabilities, even if that solution does not provide absolute protection for all persons under all circumstances. Because temporary SIP plans and methods were not developed, the concept has seldom been practiced and exercised. Because the concept has not been practiced and exercised regularly, there has been no feedback to refine and improve the concept and methods. In the meantime, because temporary SIP is a complex and possibly less-than-perfect solution to an intractable problem, many opportunities to

\footnotetext{
${ }^{13}$ Other factors that might have limited the attention given to temporary shelter in CSEPP exercises over the years include (1) the brevity of exercises, (2) the limited extents of play, and (3) the propensity to exclude the evaluation of the content of PARs and PADs until alert and notification instruments to implement PADs (e.g., sirens and tone alert radios) were installed.

${ }^{14}$ In the document Exercise Policy and Guidance for the CSEPP (CSEPP March 19, 1999 undated), Exercise Objective 3 identifies the need to open up or abandon shelters after the toxic plume has passed.
} 
educate and train the public to use a temporary SIP strategy to protect themselves in the event of a chemical accident have been deferred. 


\section{SECTION 3: CSEPP MONITORING AND MODELING IN SUPPORT OF TEMPORARY SHELTER-IN-PLACE}

The literature search discussed in this section was guided in part by the desire to answer the following questions:

- What guidance or capabilities currently exist to use computer modeling to decide when to terminate temporary SIP?

- What guidance or capabilities currently exist to use air or surface monitoring to decide when to terminate temporary SIP?

\subsection{CSEPP REPORTS}

The CSEPP Off-Post Monitoring Integrated Process Team [IPT] Report (CSEPP 1999) addresses the applicability of both monitoring and dispersion modeling to define a CWA plume and support the determination of when to terminate SIP. This report identifies dispersion modeling as the primary means to both define the hazard wedge and the plume and to determine when to terminate SIP. ${ }^{15}$ It further states that weather conditions, direct observations, and biological indicators should also be considered in making these determinations. Additionally, it states that monitoring may be used to determine egress from collective protection, especially when persistent agents are involved (p. 23). These three considerations are classified in the report as "strategies and recommendations" in a section entitled "Determine When to Egress From Collective Protection and/or Shelter-In-Place Enclosures." The exact wording (p. 23) is as follows:

- Off-post authorities should depend mainly on air dispersion modeling to determine plume passage and when to recommend ventilation and/or egress from shelter-in-place.

- In the case of collective protection, especially when persistent CWAs are involved, monitoring activities may be implemented to determine if it is safe to allow egress.

- Off-post authorities should assess factors such as weather conditions, observations, biological indicators, and models to determine egress from protective action.

\footnotetext{
${ }^{15}$ The "hazard wedge" calculated by D2PC represents the area wherein the agent plume is most likely to be. The wedge angle is dependent on stability class, e.g., Stability D is represented by a wedge encompassing 20 degrees on either side of the downwind centerline. Under existing practices, a protective action is taken for an entire zone if the wedge touches even a small portion of the zone. Thus the total area where PADs are implemented can be substantially larger than the area covered by the wedge. This artificially enlarged area makes it more difficult to change, update, or terminate PADs, an important factor in any temporary shelter strategy.
} 
While the report states that point-source monitoring can help to determine when to exit from a specific shelter, it implies that it can not be used to determine if evacuation is appropriate after exiting, nor can it provide adequate information that is applicable to the entire zone. This is because point-source monitoring can only detect what is present at the location of the monitor sampling port. The reading from one or even multiple pointsources within an area or zone will not be able to represent the entire zone. The report specifically warns that the utility of monitoring to define the vapor plume, including the time of plume passage, is limited. "The quantifiable results of one or even several monitors cannot be used to infer what CWA concentrations exist at other (even nearby) locations due to the random effects of dispersion factors present" (p. 12). The report goes on to say that monitoring may not be able to prove or disprove the accuracy of models and plume predictions (p. 12). The report provides no guidance on how a network of point-source monitors could be used to represent a larger area.

The CSEPP Chemical Detection Equipment Assessment (Janus et al. 1998), a two-volume appendix to the CSEPP Off-Post Monitoring IPT Report, was written to "summarize and assess detection equipment capable of detecting chemical warfare agents that is applicable to CSEPP off-post users." (p. 1) The report assesses the capabilities of 48 point source detectors, 5 standoff detectors and alarms, and 21 analytical instruments. The report evaluates operational parameters (i.e., agents detectable, sensitivity, selectivity/interferants/false alarms, response time, and startup time), logistical parameters (i.e., ease of operation, maintainability/supportability, and cost), physical parameters (i.e., size, weight, and transportability), and special requirements (i.e., regulations, interface requirements, and safety). The report finds that "point detection equipment is generally not sensitive or selective enough to meet user requirements. Standoff detection equipment typically requires operators with technical backgrounds and is also very expensive. Analytical instruments are usually very large, extremely expensive, require sample preparation, do not respond in real time, and require operators who are technical specialists" (p. 29).

\subsection{ARMY PLANS AND PROCEDURES}

Another key reference is the Army's pamphlet Chemical Accident or Incident Response and Assistance (CAIRA) Operations (DA PAM 50-6) (Department of the Army 1991). This document says that plans should be made for both monitoring and dispersion modeling to be a part of the hazard assessment supporting the emergency response process (paragraph 3-4c(3)). It also says that: "If sheltering is recommended, off-post authorities must be kept advised regarding plume passage.” and that: “... installations will ... provide periodic updates on ... changes in protective action recommendations." (paragraph 3-5c(5)). However, this pamphlet does not address the use of monitoring or dispersion modeling specifically to decide when and how to terminate SIP.

This document includes a Table 3-2 in the Management chapter that states that the initial hazard assessment during the response phase is characterized by speed and reference to a library of cases matching an event description with a protective action decision. The table concludes that: "While technical data is important for the decision 
process, the completion of a computerized dispersion modeling is not an essential prerequisite for initiating an alert." The table goes on to say that subsequent hazard assessments should include input from monitoring personnel, without further discussion about the use of dispersion modeling.

The Management chapter also says that:

"As further assessment information becomes available, the classification level and protective action recommendations may be adjusted. The potential effect of the CAI will be determined. This involves projecting areas of impact, the potential severity of the impact, and the timeframe of the impact. Computerized dispersion modeling techniques that predict the potential no-effects parameters will be a primary source of this information. Provisions should be made for regular and specific updates for off-post authorities as more assessment information becomes available" (paragraph $3-4 b(2)$

Taken literally, the guidance in this paragraph is ambiguous at best as to the use of modeling for making the initial PAR.

The Environmental Monitoring chapter reiterates the use of monitoring to characterize the emergency (paragraph 11-2d). This chapter does mention that "Modeling techniques may be used to complement monitoring provided the models and the computer-generated data are linked to the physical realities being measured by monitoring instruments." (paragraph 11-3a(3)(c)). The Contamination Control chapter also mentions monitoring as the way to determine if a downwind hazard exists and to establish the extent of travel (paragraph 13-2d).

This outdated concept of operations was apparently based on the assumption that there would eventually be a network of low-level real time monitors in place around chemical storage sites, and results from these instruments would be sufficient to define the extent and duration of the hazard in a straightforward manner. This was an unrealistic assumption. Instead, the Army has made significant improvements in capabilities to model agent releases quickly. Army plans and demonstrations of capability during CSEPP exercises shows that modeling is accepted as the primary tool for making PARs both during the initial response phase and for subsequent updates. Monitoring is relegated to the small but important role of helping to determine the duration of the release, and perhaps confirming the presence or absence of aerosol deposition downwind from the accident. 


\subsection{TRAINING AND INSTRUCTION FOR HAZARD ANALYSTS AND CSEPP PLANNERS}

\subsubsection{User Guides}

Numerous other CSEPP documents address the applicability of dispersion modeling to define the hazard wedge and plume and/or determine plume passage time, including the user guides for the D2PC/PARDOS and D2-Puff dispersion models. Both the D2PC/PARDOS (as integrated into EMIS/FEMIS) and D2-Puff models will calculate the set of parameters required to define the hazard wedge and plume and will identify when the plume will pass a specific location. While these documents do address data input/output, the limitations of the models, and guidance on making initial and subsequent hazard assessments, they do not directly address monitoring or egress from SIP.

\subsubsection{Training}

For years, guidance on the use of monitoring and dispersion modeling has been incorporated in training and instruction for hazard analysts and CSEPP planners as tools to help define a hazard wedge and plume and, to a lesser degree, support the determination of when to egress from SIP. The slides and handouts for the following three courses were reviewed for this effort:

- “Chemical Hazard Prediction for Decision Makers," course AMMO-T-21, (USADAC 1995).

- “Chemical Hazard Prediction for Decision Makers," course AMMO-T-22 (USADAC 1999a).

- “Chemical Hazard Prediction,” course AMMO-T-23 (USADAC 1999b).

The first course listed above is no longer taught and the content has been split into the other two courses. All three courses will be summarized here since the slides and handouts from the first course contain significantly more detail than the other two (more recent) courses.

AMMO-T-21 (1995). The materials in this course provide numerous references to the applicability of dispersion modeling and monitoring to the definition of the hazard wedge and plume as well as egressing SIP. Numerous slides address the general capabilities of the D2PC/PARDOS dispersion models and their ability to define a plume.

The materials in the course also provide insight into the approved CSEPP guidance used when making assessments to produce PARs and PADs. One slide suggests that both the initial reports from the CAI site and the daily workplan MCE should be considered in determining the source characteristic to use in the dispersion model to obtain the initial hazard assessment. The guidance states that if there is no fire, 
then the work plan MCE should be used unless the data from the CAI site indicates otherwise. If fire is involved, the guidance is to run both a fire and explosion scenario to determine which is worse. Note that the CSEPP guidance outlined here is consistent with observed practices. Other slides outline the importance of considering the plume parameters in the decision making process (presumably PADs and PARs), such as concentrations and plume travel times.

One slide is presented that discusses the difficulty in intercepting a moving plume with monitoring. Another slide recommends that a shelter can be opened if dispersion modeling predicts that the tail has passed and that spot checking (with monitors) of the concentrations in the trailing edge of the plume to validate model predictions has been done. Other slides advocate using visual sighting of smoke, dead or sick animals, people with symptoms and/or unexpected monitor readings to revise the hazard prediction, as needed.

AMMO T-22 (1999). This presentation provides guidance that is consistent with the earlier course (AMMO T-21) discussed above on the applicability of dispersion modeling to defining the hazard wedge and plume as well as the approved CSEPP guidance on making hazard assessments. Unlike the earlier course, the material in this course does not address the issue of monitoring or anything related to egress from SIP.

AMMO-T-23 (1999). This presentation provides guidance that is consistent with the earlier course (AMMO-T-21) discussed above on the applicability of dispersion modeling to define a plume. Unlike the earlier course, the material in this course does not address the issue of monitoring or anything related to egress from SIP. Furthermore, this course does not address the CSEPP guidance on making initial and subsequent hazard assessments.

\subsection{GENERAL GUIDANCE ON WHEN TO EXIT FROM SHELTERS}

The majority of the references reviewed for this report simply say to ventilate or exit the shelter once the plume has passed. Some presentations note that the time to exit is when the outside concentration is less that the inside concentration. Consider, though, that the outside concentrations have the potential to fluctuate, which will tend to cause a higher toxic load than would otherwise be expected if one just looked at the mean concentration predicted by the model.

In most cases, the decision to terminate SIP should be based, at least in part, on the concentration history of the agent plume. In many cases, the optimal time to terminate SIP should be when the tail of the hazardous plume has passed the shelter. Selecting the optimal time might be compromised since PADs and PARs usually apply to an entire zone or large facility, and not to a single shelter. The difficulty arises especially with large zones, where it can take significantly longer for the tail of the plume to reach the farthest end of the zone (i.e., the point farthest from the release) than the time it takes to reach the closest point in the zone. This is most problematic for scenarios where 
immediate exit from shelters is time critical (e.g., when there are life threatening toxic effects from indoor concentrations).

\subsection{TOOLS AND MODELS}

\subsubsection{Dispersion Models}

The two approved dispersion models for CSEPP are D2PC/PARDOS (IEM 1993) and D2-Puff (Prater 1998). Currently, only the D2PC/PARDOS models results are being used to make an initial PAR since the D2-Puff model has not yet been integrated into the EMIS/FEMIS program.

D2PC is a simple, Gaussian plume dispersion model which tends to over-predict agent concentrations for a variety of reasons. The D2PC model does not calculate agent concentrations as a function of time, and, therefore, the PARDOS model is run with the output of the D2PC model to calculate the time-dependent nature of the plume, including plume arrival and departure time. Even though PARDOS predicts the time-dependent nature of the plume, the interpretation of that data in EMIS/FEMIS assumes a linear biological response to the agent (i.e., the current CWA toxicology).

The D2PC Reference Manual (p. 10-33) lists the following reasons why the model over predicts concentration:

- The model assumes steady-state diffusion over open, flat terrain. (Accounting for terrain and vegetation creates more turbulence, or mixing, which reduces the expected downwind safety distances.)

- The model assumes constant wind direction. (Wind shifts would reduce expected exposure and spread the plume over a wider area.)

- The model outputs the peak, centerline values. (Off-axial values would be lower.)

- The model assumes total exposure/dosage, i.e., the entire plume has passed. If the plume takes six hours to pass a particular location, the model assumes the person exposed at that location will be stationary in the plume centroid for the entire plume duration while breathing the agent.

- The model assumes a breathing rate of 25 liters per minute, equivalent to moderate work activity. (Lower breathing rates would reduce agent inhalation intake.)

- For most releases, the model assumes a "point source" (zero volume), which maximizes the downwind concentration close to the source. 
- The model assumes the exposure occurs outdoors. (Concentration levels will always be lower indoors).

While the D2PC model can account for vapor depletion (i.e., agent vapor that is removed from the plume due to contact with soil, grass, trees, etc.), the recommendation is not to account for vapor depletion, which increases the downwind vapor concentration predictions.

The D2-Puff model is a puff-type dispersion model, and it tends not to overpredict agent concentrations as much as D2PC. Unlike D2PC, D2-Puff considers terrain features as well as changes in wind direction. As a puff model, it can directly account for the wind meander. Additionally, D2-Puff is not subject to as many limitations as a plumetype model and consequently can more accurately predict agent concentrations. Like PARDOS, the D2-Puff model can predict when the agent cloud has passed a given location. Version 3.0 of D2-Puff is designed to use the most recent CWA toxicological information such as contained in the AEGLs.

\subsubsection{Surface Contamination}

While the CSEPP IPT Off-Post Monitoring Report discusses the potential usefulness of monitoring for surface contamination prior to allowing egress from collective protection, especially for persistent agents, the degree to which surface contamination might be an issue is a controversial one. The U.S. Army Generation of Assessment Patterns for Clouds of Airborne Particles (GAPCAP) model (Wu, 1986) is the only model used in CSEPP to estimate deposition of CWA particles. GAPCAP is a Gaussian model designed to describe the transport and diffusion of small CWA particles released into the atmosphere. GAPCAP is not designed as a response tool, and is not available at Army chemical stockpile storage sites. The GAPCAP model was the basis for a two-volume study by Argonne National Laboratory about the potential for surface contamination by deposition of chemical agent following accidental release at an Army storage depot (Paddock et al., Argonne National Laboratory, unpublished information, 1994). The study concluded that persistent agent aerosol deposition may, under certain scenario and atmospheric conditions, be an issue off-post for some large releases of persistent agents. Unfortunately, the study is not conclusive because it did not consider a number of relevant factors, including wind meander, increased turbulence due to terrain features, deposition on foliage and evaporation, which will tend to reduce the deposition levels predicted by the model. The results of the ANL study provide only general guidance on the magnitude of potential deposition, and cannot be applied to specific scenarios.

ANL asked Michael Myirski for information about how the potential for aerosol deposition can be factored into deciding when and how to terminate SIP. ${ }^{16}$ He said:

"In the absence of dependable quantitative calculations about the potential for aerosol deposition associated with a chemical accident, there is little

\footnotetext{
${ }^{16}$ Michael Myirski is an SBCCOM expert on dispersion modeling of CWA releases.
} 
choice but to use qualitative estimates to judge the potential for aerosol deposition. Initial judgements should be based on the best available information about the release, atmospheric conditions at the accident site and down wind, and the expert knowledge of Army hazard analysts. These informed judgements should be adjusted immediately as new information becomes available. This is not unreasonable, considering that the generation of aerosol deposition beyond the installation boundary is such a remote possibility, and the conditions that would generate aerosol deposition are easily identified. ${ }^{17}$ The absence of these indicators justifies ignoring aerosol deposition completely when making temporary SIP decisions. If aerosol deposition is indicated, Army hazard analysts should make an informed judgement based on the best available information. Reports from surface monitoring teams can help if they are obtained quickly. Regardless, the analysis of any release should consider the potential for an aerosol deposition hazard, and Army PARs should always include an assessment of this potential."

\subsubsection{PAECE and PADRE Computer Models}

The PAECE (Protective Action Evaluator for Chemical Emergencies) and PADRE (Protective Action Dosage Reduction Estimator) computer models were developed by Oak Ridge National Laboratory and were designed specifically for CSEPP to help develop protective actions for chemical emergencies. These models are designed to compare SIP with evacuation. The PAECE model (Rogers and Sharp 1990), which was more of a research-oriented tool, was the predecessor to the PADRE model. The PADRE model (Naegli 1998) was designed to be both a planning and operational tool. Warning-system effectiveness and human behavior in response to an emergency are factored into the PADRE model. The user of PADRE inputs the characteristics of a chemical agent release, the meteorology, shelter infiltration rates, the emergency response system, and evacuation times, in order to compare dosages received for unprotected individuals and individuals taking protective actions. The model is also designed to account for the probability of completing a protective action, and will predict dosages received for scenarios where a protective action is not executed at the appropriate time (e.g., an expedient shelter is secured after significant infiltration has occurred, which effectively traps agent inside the shelter). The D2PC/PARDOS dispersion models are integrated into the PADRE model and the parameters of the plume (e.g., concentration history; plume arrival and departure times) are used to determine the resultant dosages from various protective actions.

The PADRE documentation suggests that egress from shelter should take place once the concentration outside the shelter is predicted by dispersion modeling and

\footnotetext{
${ }^{17}$ An unusual combination of factors is needed to make aerosol deposition a possible health risk beyond the immediate accident site. It requires many explosively-configured munitions filled with persistent agent (VX or mustard) to create large particles or aerosols upon detonation, a fire hot enough to cause the munitions to detonate, and atmospheric conditions that will transport the aerosol significant distances.
} 
supported by monitoring results to be less than inside the shelter. On this subject, the PADRE model users on line help guide states

"Determining the best time for vacating a shelter at a specific location can be very hard, and determining the best vacating time for an entire subzone is even more difficult. If people vacate early, they may get exposed to high levels of toxic agent still present in the outside air. If they vacate too late, they may unnecessarily expose themselves to agent vapor trapped inside the shelter while the outside concentration of agent vapor already has fallen below the inside concentration. If people fail to vacate the shelter long after the outside air is clean, they may accumulate a dosage that greatly exceeds the unprotected dosage they would have received if not taking any protective action at all!"

The PADRE documentation also discusses the inherent difficulty in the use of dispersion modeling/source characterization to get a representative plume departure time.

The toxic effects calculated in the PADRE model are based on the current toxicological information that assumes a linear biological response to the CWAs. During the course of the literature search, no evidence could be found that either of these models is currently being used within CSEPP.

\subsubsection{Alabama CSEPP Protective Action Recommendation Guidebook}

Innovative Emergency Management (IEM) has prepared a guidebook to help the Anniston communities determine if they should shelter-in-place or evacuate during a chemical accident/incident (CAI). The Alabama CSEPP Protective Action Recommendation Guidebook (IEM 2000a) and the associated Technical Addendum to Alabama CSEPP Protective Action Recommendation Guidebook (IEM 2000b) are designed to allow decision makers at Anniston Chemical Activity (ANCA) to decide between evacuation and SIP PARs during a CAI response. The 10-step IEM guidance requires the user to apply scenario-specific parameters (i.e., type of munitions, type of agent, amount released, season, and meteorological conditions) as well as the plume arrival and departure times for a given zone (as predicted by D2PC/PARDOS) to determine if evacuation or SIP is the better option. Built into the guidance in the handbook are additional parameters, such as diffusion warning times, mobilization times, and shelter air exchange rate (i.e., $1.94 \mathrm{ACH}$ ). The assumption for this guidance is that SIP will be a temporary protective action and egress from SIP will be required. The plume departure time (for the zone) is used to determine when to egress from SIP. The IEM guidebook simply states that they believe that the best time to egress from SIP is "shortly after the tail of the plume has passed" (Addendum, p. 5). This guidebook acknowledges that some policy on this matter is needed to support this assumption. The D2PC plume concentrations predicted during the response are not used directly in this methodology - rather the relative toxic effects are based upon one of six baseline 
scenarios. ${ }^{18}$ It is important to note that this methodology used the current toxicological information on the CWAs in determining the relative toxic effects of the six baseline scenarios. The relative toxic effects using the proposed toxicological information would likely be different.

\subsection{ANALYSIS}

\subsubsection{Dispersion Modeling}

All of the literature that was reviewed in this section that addressed the issue of egress from SIP assumed that the optimal time to egress from SIP is after the plume has passed. For the purpose of this project that should not be an underlying assumption; rather it should be challenged and validated during Task 2 . The precise role that plume definition will play in the methodology for determining egress from SIP, which will be included in Task 2 of this project, is not yet known. However, on the basis of this literature search, it will likely play some role in that methodology.

The literature indicates that dispersion modeling is a critical component in defining the concentration history of a plume as well as making the determination to egress from SIP. The D2PC/PARDOS dispersion models that are currently in use tend to over predict agent concentrations for a wide variety of reasons. The effect of this overprediction of concentrations on the determination to egress from SIP was not addressed in any of the literature reviewed. This should be considered in Task 2 of this project. In addition, the differences between D2PC/PARDOS and D2-Puff discussed in paragraph 4.5.1 should also be considered in Task 2 .

Ideally, all of the pertinent release characteristics of a chemical agent accident including the type and amount of agent released, mode of release (e.g., fire, evaporation, explosion) and the duration of the release would be known at the start of the accident. That would allow hazard analysts the opportunity to define the hazard wedge and the plume in space and time, and make the best determination of when to egress from SIP. Unfortunately, it is unlikely that all of the pertinent release characteristics of a chemical agent accident will be known immediately, if ever. Therefore, hazard analysts and decision makers must develop PARs and PADs on the basis of incomplete information. The chemical hazard prediction training materials (USADAC 1995, 1999a, b) address this issue in part. They suggest that hazard analysts (1) use the work plan MCE unless there is data from the CAI site that indicates otherwise for non-fire scenarios, and (2) select the greater hazard between a fire and explosion scenario when fire is reported. Additionally, the training materials recommend that reassessments be made as new information from the field comes into the EOC.

For those scenarios where the dispersion modeling inputs default to the MCE and/or where a worst-case set of inputs are used (i.e., fire scenarios) the ability to make a meaningful decision on when to exit from shelters may be compromised. In these cases,

\footnotetext{
${ }^{18}$ The baseline scenario is selected in Step 1 of the 10-step process on the basis of the scenario-specific parameters.
} 
applying the MCE (for example) to model the vapor plume from a release might result in (1) significantly higher or lower concentrations than actually exist and/or (2) plumes of significantly longer or shorter duration than actually exist. For making the determination to egress from SIP, the most problematic case is when the MCE scenario predicts a plume that is shorter in duration than the actual plume, since it can result in direction to exit temporary shelters prematurely. ${ }^{19}$ Therefore, the use of the MCE in association with current CSEPP guidance on making initial and subsequent hazard assessments will be reviewed for application to temporary SIP during Task 2.

\subsubsection{Monitoring}

A vapor plume is not homogeneous throughout the volume of air in which the vapors are present. Depending on the meteorological conditions, concentrations of vapors in the plume can vary significantly even over short distances. In addition, even though a CWA plume might be somewhat negatively buoyant near the point of release, in certain terrain there might be no detectable vapor near the surface but relatively high concentrations just overhead and nearby. Compounding the challenge to characterize the plume are the capabilities monitoring instruments would need to be able to track the plume. One can certainly understand why the CSEPP Off-Post IPT Monitoring Report was unsuccessful in identifying a dependable portable instrument that is quick to start up and easy to use, that could track low concentrations of vapor in the plume in real-time to make temporary SIP decisions based on monitoring results. This is why the CSEPP OffPost Monitoring IPT Report concluded that delayed sheltering strategies should be driven by preplanning and models, not by monitoring (p. 11). This is also why Army CAIRA plans do not attempt to "chase the cloud." None of the literature considered during this search offered a different or better conclusion about monitoring to support temporary SIP decisions. However, results of monitoring on-post immediately following an agent release might have some utility in deciding the timing of temporary SIP actions. This concept will be explored in Task 2 .

Regardless of the purpose for monitoring, the literature is generally consistent about the meaning of a confirmed positive reading from a point-source air monitor. For a non-persistent agent release, a positive reading indicates only that agent vapor is present at that location at that time, and the source might be either the agent cloud or trapped residual vapors. For a persistent agent release, a positive reading indicates only that agent vapor is present at that location at that time, and the source might be the agent cloud, trapped residual vapors, or surface contamination.

The literature is not consistent about what negative monitoring readings mean, assuming that the instrument is operating properly in the first place. Some literature

\footnotetext{
${ }^{19}$ In some cases, the MCE attempts to "safe-side" the release characteristics by assuming that the release occurs rapidly. That results in a relatively high estimate of maximum concentration levels. This assumption results in protective actions that are intended to be conservative, but the "rapid release" assumption may create a problem in terms of the timing of egress from SIP. If the release actually occurs more slowly than predicted using the MCE, persons might exit their shelters into the plume. This is neither a "safe-sided" nor a conservative action.
} 
suggests that a negative reading by itself can verify that the plume has passed; other references suggest that a negative reading that is consistent with modeling results can verify that the plume has passed; and still other references suggest that a negative reading cannot indicate anything definitive.

Furthermore, while some references indicate that a negative reading can be used to determine when to exit from a specific shelter, they do not provide guidance on how individual monitoring results can be applied to an area or an entire zone. The latter issue is vital because protective action decisions are usually made for an entire zone, or at least the part of the zone within the hazard wedge.

The literature references to the use of visual sighting of smoke in defining the plume, and in making the egress from SIP determinations, might have some merit in certain release scenarios during daylight hours. This will be considered in Task 2. Also, some of the literature suggests that the presence of dead or sick animals and/or people with symptoms can be used to help define the plume and/or help make temporary SIP decisions. This will also be explored in more detail in Task 2 but is not a promising avenue. Since observed toxic effects may or may not tell the observer about when or where the exposure took place, it is difficult to relate this information to the current plume characterization. 


\section{SECTION 4: GUIDANCE FROM OTHER PROGRAMS ON TEMPORARY SHELTER-IN-PLACE}

The literature search discussed in this section was guided in part by the desire to answer the following questions:

- What guidance, information, or lessons learned about terminating temporary SIP can be found in the literature outside of the CSEPP?

- Have there ever been any real-world chemical releases where timely termination of temporary SIP was practiced, and with what results?

- Should persons relocate or evacuate after departing from a temporary SIP? (Considerations include risk of residual vapors or low levels of aerosol deposition outside of the shelter, availability of transportation, accessibility of evacuation routes, and need for immediate medical surveillance of the population that sheltered-in-place.)

- How much protection does normal, expedient, and enhanced sheltering provide against vapor infiltration, and for how long?

\subsection{EXISTING AUTHORITIES}

Some of the guidance discussed below pertains to radiological rather than chemical hazards. This guidance was developed by the FEMA, the Nuclear Regulatory Commission (NRC), and the EPA primarily for communities preparing for the possibility of a nuclear power plant accident. The health effects of exposure to radioactivity are, of course, quite different from those of exposure to chemical agents. However, the two hazards also have some similarities relevant to emergency planning: harmful concentrations can be invisible and undetectable without instruments; there is potential for acute or long term effects; they may be released as vapor only or may involve the possibility of deposition; and protective actions may be required up to several miles downwind. For that reason, these guidance documents were included in the literature search.

\subsubsection{North American Emergency Response Guidebook}

The U.S. Department of Transportation's Research and Special Programs Administration issued the 2000 Emergency Response Guidebook; A Guidebookfor First Responders During the Initial Phase of a Dangerous Goods/Hazardous Materials Incident, available at http://hazmat.dot.gov/gydebook.htm. It contains descriptive material and response guidance for each of the hazardous material code numbers that appear on the required placards found on trucks and railroad cars. It also has a general section on protective actions for the public. According to that section, 
"In-place protection is used when evacuating the public would cause greater risk than staying where they are, or when an evacuation cannot be performed." It also states that "In-place protection may not be the best option if (a) the vapors are flammable; (b) if it will take a long time for the gas to clear the area; or (c) if buildings cannot be closed tightly. Vehicles can offer some protection for a short period if the windows are closed and the ventilating systems are shut off." Although it does not specifically address temporary SIP or warn that ventilating or vacating the premises may be necessary to minimize exposure, the guidance does advise that "[it is] vital to maintain communications with competent persons inside the building so that they are advised about changing conditions" (RSPA 2000, p. 314).

\subsubsection{Criteria for Preparation and Evaluation of Radiological Emergency Response Plans and Preparedness in Support of Nuclear Power Plants}

In 1980, FEMA and NRC issued the guidance document Criteria for Preparation and Evaluation of Radiological Emergency Response Plans and Preparedness in Support of Nuclear Power Plants, NUREG-0654/FEMA-REP-1, Rev. 1 (NRC/FEMA 1980). This document is intended to advise communities near nuclear power plants. Appendix 1 of that document, entitled "Emergency Action Level Guidelines for Nuclear Power Plants," describes classification of power plant emergencies into four categories, the most severe of which is a "general emergency." The appendix states that "The general emergency class involves actual or imminent substantial core degradation or melting with the potential for loss of containment. The immediate action for this class is sheltering (staying inside) rather than evacuation until an assessment can be made that (1) an evacuation is indicated and (2) an evacuation, if indicated, can be completed prior to significant release and transport of radioactive material to the affected areas." This guidance was modified in July 1996 with the issuance of a supplement, Criteria for Protective Action Recommendations for Severe Accidents (NRC/FEMA 1996). After reviewing extensive studies, NRC staff concluded that their position had "evolved from the position in NUREG-0654," and unless there is some constraint on the ability to evacuate, "in the event of a severe (core damage) accident, the preferred initial protective action is to evacuate the population promptly rather than to shelter the population near the plant . ..." The supplement references two other documents, Manual of Protective Action Guides and Protective Actions for Nuclear Incidents (EPA 1992) and Response Technical Manual 96 (NRC 1996).

As explained in the supplement, having people seek SIP if they cannot evacuate before the plume arrives was considered to apply only for a short-term (puff) release of known duration. More recent studies have shown that for other than containment venting, this type of release is not predictable, and most of the release and accompanying dose for a long-duration release can be avoided by evacuating early. In addition, studies have shown that except for very limited conditions, evacuation in a plume is still more effective in reducing health risks than prolonged sheltering near the plant: 
“... The basic premise is that in the unlikely event of a severe core damage event, plant operators cannot predict with certainty the occurrence of a radiological release, the magnitude and duration of any such release, or the radiological consequences of the release. The staff has considered these uncertainties and has recognized that sheltering people in most structures close to a nuclear power plant, where plume concentrations and dose consequences are likely to be highest, will not prevent early adverse health effects during a major radioactive release. Accordingly, the staff has concluded that it is better to evacuate promptly near the plant for a serious reactor accident as a precautionary measure rather than to wait for additional information that may only become available after a release occurs" (NRC/FEMA 1996, p. 3).

This guidance does not explicitly address temporary SIP or when to ventilate shelters. The discussion limiting sheltering to "puff" type releases of "short duration," while not quantified, indicates that the guidance authors were looking for situations where the exposure time would be relatively short and the sheltering time would be limited. The general emphasis on evacuation as protective measure would seem to indicate that evacuation would be favored after a brief sheltering spell following a "puff" type release.

\subsubsection{Manual of Protective Action Guides and Protective Actions for Nuclear Incidents}

In EPA's Manual of Protective Action Guides and Protective Actions for Nuclear Incidents (EPA 1992), Sections 5.5.2 and 5.5.3 discuss use of sheltering as a protective action and deciding between sheltering and evacuation. These sections indicate that sheltering may be appropriate when evacuation is impeded, e.g., by severe weather or floods, or for specific populations that have evacuation constraints, such as patients in hospitals or nursing homes. For situations where inhalation is the primary exposure pathway (as opposed to ingestion or gamma ray "shine" from airborne or deposited material), this document emphasizes the importance of ventilation control and temporary SIP: "Following plume passage, people should open shelters to reduce airborne activity trapped inside, and they should leave high exposure areas as soon as possible after cloud passage to avoid exposure to deposited radioactive material." In terms of deciding between evacuation and sheltering, the document notes that "the process of evaluating, recommending, and implementing evacuation or shelter for the public is far from an exact science" but offers some general principles: evacuation will provide total protection if it can be completed before arrival of the plume, but evacuation may increase exposure if carried out during plume passage; sheltering can be implemented more quickly, and it positions the public to receive further instructions. On the other hand, sheltering "is usually not appropriate where high doses are projected or for exposure lasting longer than two complete air exchanges of the shelter." Although it does not explicitly advise decision makers on when to implement temporary SIP, the latter point does suggest a rule of thumb of evacuating after a period equal to two times the average air exchange period. 


\subsection{SCHOLARLY PUBLICATIONS}

Numerous journal articles, government reports, conference papers, and the like have been written on the use of SIP as a protective action against airborne hazards. A partial list is provided in the bibliography. Following is a summary of the some of the key works, specifically those relating to the protective action decision making process and instructions to the public for SIP. These works have been cited frequently in subsequent articles, guidance documents, and reports.

\subsubsection{Indoor Air Quality and HVAC Systems}

Indoor Air Quality and HVAC Systems (Bearg 1993) is an example of many references that said essentially the same thing about the time it takes to ventilate a shelter. The time it takes to ventilate a shelter depends on the following factors:

- The air exchange rate you can achieve during the ventilation mode of operation.

- The initial agent concentration in the shelter before ventilation starts.

- The acceptable agent concentration (i.e., how clean does it need to be).

For a given set of these parameters, one can calculate the time required to ventilate a shelter. Note that the calculation is not a function of the type of shelter (i.e., normal, expedient, or enhanced), since shelters are classified based on their potential to prevent infiltration (during the "shelter" mode of operation) and not on their ability to ventilate.

\subsubsection{Proceedings of the Conference on In-Place Protection During Chemical Emergencies (1988)}

The proceedings volume of the 1988 Conference on In-Place Protection During Chemical Emergencies (Glickman and Ujihara 1988) includes summaries of the conference sessions, conclusions, and appendices containing background documents and materials.

Session 1 was devoted to field experience and included presentations by John "Ikey" Lucas of St. Charles Parish, LA; Mike Hildebrand of the American Petroleum Institute; Larry Bissett of NICS; and David Palmer of Emergency Response Planning and Management, Inc. The following are key points made during this session.

- St. Charles Parish primarily relies on SIP since "there is rarely adequate time to evacuate following chemical releases."

- The 1976 Houston anhydrous ammonia incident demonstrated the potential benefits of SIP and "[the National Transportation Safety Board has] documented numerous cases where those who stayed indoors or in their cars 
received much less exposure and thus much less injury than those who did not."

- The public generally lacks confidence in SIP; in the Kanawha valley (a highly industrial area in West Virginia) a citizen's group newsletter advocates fleeing immediately at the first trace of an unusual smell.

Session 2 on related research included presentations by Ted Glickman of Resources for the Future, Michael Lindell of Michigan State University, John Sorensen of ORNL, and David Wilson of the University of Alberta, Canada. The following are key points made during this session.

- Survey data indicates the public is skeptical of SIP, and about one-half of those surveyed said they would prefer to evacuate rather than obey an order to SIP.

- Conditions that maximize public compliance with a shelter order are: (1) timely warning, (2) effective warning messages, (3) a clear rationale for SIP, (4) an absence of visual cues (such as visible plume), (5) high credibility of response personnel, and (6) pre-emergency education.

- Leakiness of U.S. houses varies by about a factor of five. Wind speed has a large effect on infiltration rates.

Summaries of the other sessions do not contain significant discussion of points relevant to temporary SIP. The appendices include excerpts from a variety of technical guidance documents, reports, and public information documents. The information they contain on SIP decision making is quite general, with the exception of the papers by Dr. David J. Wilson, which are treated separately below.

\subsubsection{Proceedings from Protecting the Public: A Conference on Protective Actions During Chemical Emergencies (1995)}

The proceedings volume from Protecting the Public: A Conference on Protective Actions During Chemical Emergencies, held in 1995 by the National Institute for Chemical Studies (NICS 1995), includes abstracts and presentation materials from conference speakers. The conference included panels on the following topics:

- How effective is sheltering-in-place as a public protection technique?

- How can the most effective protective actions be selected?

- How can public response to protective action instructions be improved?

The first panel included presentations by Robert J. Gardner of the DuPont Company, George O. Rogers of Texas A\&M University, and Chief John M. Eversole of 
the Chicago Fire Department. Mr. Gardner presented the results of a study on the effectiveness of sheltering against toxic chemicals using quantitative risk estimation methods. The study looked at a range of release types, using the assumption that more severe accidents are less likely than minor ones. An example was presented of a hypothetical chlorine release with analysis of the risk of fatal injury $800 \mathrm{ft}$. from the facility with and without SIP. The study found that SIP reduced the risk in all cases but especially for those cases where the release duration was 15 minutes or less.

Dr. Rogers presented the results of his studies done in conjunction with ORNL relating to chemical agent emergencies. They looked at peak exposures and cumulative exposures for unprotected persons and persons using normal, expedient or enhanced shelter, which are characterized as "leaky" shelter. The studies indicated that for such leaky shelters,

- The longer the release, the less likely sheltering can be effective.

- The more cumulative the effects, the less likely sheltering can be effective.

- The more tractable the plume, the more likely sheltering can be effective.

The presentation also stated that "if in doubt, move them out." The presentation also touched on several factors affecting timing: the timing of protective action decisions, the length of time required for public warnings to be disseminated, and response time by members of the public after hearing the warning. For all of these factors, a graph of action versus time yields a steep initial curve over the first few minutes. The graph then flattens out and asymptotically approaches $100 \%$ over a longer period.

Mr. Eversole's presentation focused on decision making by Incident Commanders and included descriptions of several past incidents and responses. He referred to an anhydrous ammonia release in Houston in 1976, in which people who stayed in their cars and houses received less severe injuries than those who got out and tried to escape. He stressed that members of the public will do their own decision making in an emergency and will tend to favor evacuation. That is a natural reaction to danger. Education is needed in order to establish the value of SIP in the public's mind.

The second panel included presentations by representatives of several private and government organizations. The presentation most relevant to this report is that by Diane Ogren of the Michigan State Police. The materials associated with Diane Ogren's presentation included a 30-page "Warning, Evacuation \& In-Place Protection Handbook" published by the Michigan State Police Emergency Management Division. The handbook has a checklist of pros and cons for SIP to aid planners and decision makers. It also has a section devoted to "In-Place Stay Time." This section discusses the studies performed by Drs. Wilson and Rogers concerning air infiltration into structures. It instructs that

"Once the plume has passed, the contaminated air is trapped inside the structure until clean outdoor air infiltrates. This process can be speeded up 
by giving an 'all clear' signal that instructs persons to open doors and windows and ventilate the structure. This is an important action in the cycle of in-place protection implementation."

However, no specific guidance is given as to when to deliver the "all clear" or how to make that decision. The Michigan handbook also discusses use of expedient SIP, although that term is not used. There is a discussion of maximum possible stay times in sealed rooms. This discussion appears to be based on the assumption of a truly sealed room with zero air exchange; the stay times are then determined by the interval until the occupants' respiration renders the air toxic due to high carbon dioxide levels. For most situations this takes several hours. However, it appears unlikely that a room subjected to expedient or enhanced shelter measures would achieve that level of airtightness.

The handbook also contains four appendices with short case studies of toxic chemical releases and responses including both evacuation and SIP. SIP was judged an effective protective action in at least two of the cases.

\subsubsection{Proceedings from Protecting the Public: A Conference on Protective Actions During Chemical Emergencies (1999)}

NICS followed up the 1988 and 1995 conferences on chemical emergency management with a 1999 conference in Concord, California entitled "Protecting the Public '99: A national conference on protecting the public during chemical emergencies." The proceedings from that conference include a talk by William K. Blewett of the Edgewood Chemical Biological Center, reporting on two studies conducted for the CSEP program on protection factors offered by sheltering. One study measured the effectiveness of expedient sheltering in reducing air exchange in a typical bathroom with a window or a walk-in closet without vents. Overall protection factors based on air exchange were estimated for 12 houses, assuming either a 10-minute exposure or a 1hour exposure. For the 10-minute exposure, protection factors ranged from 39 to 101, and for the 1-hour exposure they ranged from 7 to 17 .

The second study looked at the effect of filtering by the building shell on protection factor. Air entering the building is filtered to some degree as walls, curtains, etc. absorb some of the contaminant. A small cottage was built for the study and exposed to methyl salicylate, mustard gas, and the nerve agent sarin. The study found a significant filtering effect that increased protection factors by 2 to 3 times for sarin and 15 to 50 times for mustard.

Dr. Dennis Mileti spoke at a luncheon during the conference and discussed the warnings and public education. The main points of his presentation have relevance to CSEPP and how to communicate PADs on SIP.

- People do not panic when warnings are issued. 
- When you need people to evacuate or SIP, the problem is convincing them that they are at risk. If there are not environmental clues, people are less likely to believe they are at risk.

- Short warnings that do not supply the public with what they need will prompt them to get information, or misinformation, from somewhere else.

- Try to have multiple spokespersons issue warnings. The population is diverse, and needs to be warned in different ways.

- Repeat warnings over and over.

- Do not depend on people to remember siren patterns.

- If the family isn't united, it's much less likely to take a protective action.

The conference proceedings also included a post-conference assessment by David S. Palmer, president of Emergency Response Planning \& Management. He noted that although considerable laboratory and field research has been done on the effectiveness of sheltering in place, "effective application of such technical information at the community level may not be the typical situation. The issue of effective incorporation of research results into community planning for and implementation of protective action appears to continue as a priority." The post-conference assessment goes on to call for development of guidance on use of SIP as a "default" protective action and optimum sheltering times for defined structure types and weather conditions. It also calls for case studies on actual instances of sheltering and how effective it was in those situations.

\subsubsection{Papers by Dr. David J. Wilson}

Dr. David Wilson of the University of Alberta, Canada, has published a series of scholarly papers on the effectiveness of SIP in chemical emergencies. These papers are frequently cited by other scholarly works and handbooks. They generally advocate use of sheltering rather than evacuation for many hazardous release situations. Dr. Wilson also stresses the importance of the non-linear biological response to toxic chemicals. Some of the most pertinent are summarized below.

“Stay Indoors or Evacuate to Avoid Exposure to Toxic Gas?" (Wilson 1988). This paper considers the effectiveness of sheltering against a sudden release of "sour gas" (hydrogen sulfide). It examines research on air infiltration into houses and how concentrations indoors and outdoors would likely change over time following a release. The paper finds that for fairly tight houses (as typically found in the cold climate of Canada), SIP reduces the expected peak concentration to which an individual will be exposed by roughly a factor of 50 for a 7-minute release, a factor of 8 for a 1.2-hour release, and a factor of 2 even for a 12-hour release. This is particularly important for gases such as hydrogen sulfide where biological effects are mainly a function of peak concentration rather than cumulative exposure. A key fact pointed out in the study is that 
due to turbulent mixing following a release, outdoor concentrations of the chemical would likely vary widely by locale and would also fluctuate considerably over time at any given location. The plume models usually provide an "averaged" contour that indicates probable average concentrations for particular locations and times, but in the real world there would be great variations within these areas. SIP dampens the extremes of these variations since the house is essentially sampling the outdoor air over a longer period of time.

"The Influence of Non-Linear Human Response to Toxic Gases on the Protection Afforded by Sheltering-in-Place" (Wilson and Zelt 1990). This paper examines a scenario with a rather leaky house $(2 \mathrm{ACH})$ and a 1-hour release. As stated in the paper: "The indoor concentration rises to about $80 \%$ of the outdoor value, and people remaining indoors are exposed to high concentrations long after the outdoor toxic cloud has passed by. This seems to show that indoor shelter offers little or no advantage over evacuation through the outdoor toxic gas cloud." The paper maintains that this is misleading because for many toxic gases, biological response is non-linear; therefore peak concentration is more important than cumulative exposure. Additionally, the damping effect that sheltering has on the fluctuating concentrations outdoors offers significant protection. He concludes that "in most cases it is better to shelter indoors rather than attempt an evacuation while a toxic release event is in progress."

\section{"Ordering Shelter or Evacuation During an Outdoor Toxic Gas Release} Incident: The C.A.F.C. Decision Flow Chart," (Wilson and Morrison 2000). This paper, presented at the annual meeting of the Canadian Association of Fire Chiefs (CAFC), discusses an "evacuate or shelter decision flow chart" for use by emergency responders and explains its technical basis. The flow chart is based on planning that defines a close-in "initial isolation zone" and a surrounding "protective action zone." It also relies on two protective action concepts: "supervised evacuation" and "adequate protection from shelter-in-place." Supervised evacuation is defined as an evacuation in which the public is specifically warned as to the nature of the hazard and instructed on evacuation methods and safe routes and in which reception centers and movement assistance are available. Adequate protection from SIP is defined as implying that people sheltering will not exhibit symptoms that require immediate care by first responders or medical personnel.

The flow chart provides a decision tree for evacuation vs. sheltering for the initial isolation zone and protective action zone, based on whether the release has started, whether supervised evacuation is available, and whether SIP provides adequate sheltering. If a release has started and supervised evacuation is available, the chart provides that the initial isolation zone should be immediately evacuated, and the protective action zone be initially sheltered. The sheltering decision should then be reviewed periodically (every 15 minutes to two hours, depending on circumstances) to determine whether sheltering still provides adequate protection. If not, then evacuation should be implemented. The chart does not address how sheltering ends, except through the decision criterion that it no longer provides adequate protection. 


\subsection{6 "Shelter-in-Place: Planning and Implementation"}

The paper "Shelter-in-Place: Planning and Implementation" was prepared by the Agency for Toxic Substances and Disease Registry (ATSDR) (U.S. Department of Health and Human Services undated). It analyzes the results of studies on protective measures that were presented at the conferences discussed above and examines computer air dispersion models for some common hazardous materials. It summarizes (1) when SIP is an appropriate response, (2) when other options should be exercised, (3) how and when sheltering should be implemented, and (4) when and how sheltering should stop.

The paper emphasizes that planning should be specific to the hazard and community. Planners must take into account studies of technical factors such as plume dispersion and air infiltration, and also the human behavioral aspect of how people react to an instruction to take shelter. Both types of information are necessary to determine how effective sheltering will be and also to determine the crucial element of timing: given the nature of the hazard and the proximity of the public, can sheltering be implemented in time to reduce exposure? Studies have shown that unpracticed communities take approximately 60 minutes to "button up." Practiced communities take only 25 to 30 minutes. Sheltering can reduce exposure if timed correctly vis-a-vis plume arrival, but it can actually increase exposure if timed poorly.

The paper suggests that SIP plans should specify "once implemented, how it will be determined that shelter-in-place can be lifted" (p. 3) and discusses methods for doing so. The last section of the paper is entitled "When and how to end the shelter-in-place process?" This section states that "Ideally, as soon as the cloud passes, the shelters should be opened and ventilated and the population should leave the area, either upwind or crosswind, until an all-clear signal is sounded" and further states that "cloud passage should be verified and not simply modeled" (p. 6). However, the latter statement appears to be predicated on the assumption that air monitoring can be done in a manner prompt and accurate enough to support the exit decision.

The paper also gives several suggestions for how to implement temporary SIP and return. It advises that the public be instructed, upon return to evacuated areas, how to recognize hazardous material residues or residual effects and what to do if residual effects are detected. It also advises holding a public meeting within 24 hours after the return to field questions from the public and media.

\subsection{MEDIA REPORTS OF SIP}

A database search was performed to locate recent newspaper articles reporting use of SIP. Numerous articles were found that mention use of SIP in response to hazardous material releases. The articles contain little in the way of discussion regarding criteria for declaring "all clear." It appears that the usual practice has been to use SIP indefinitely until the emergency has been resolved; in these reported incidents, often the release is over or has been determined to be non-hazardous within an hour or two. 
Although public reaction was not one of the search criteria, a considerable proportion of the articles retrieved contain some mention of problems with public acceptance of SIP — either noncompliance with an order, or protest at public meetings.

Following are summaries of the most salient events.

- Officials in Iberville Parish, LA, used four sirens and an automated telephone system to warn residents to SIP on February 24, 2000, following reports of a foul odor (Advocate 2000). The odor was eventually traced to a small release of trimethylamines, which have a strong odor but did not pose a danger to residents.

- Officials in Kanawha and Putnam Counties in West Virginia called for SIP in certain areas when a smoky fire broke out in the Flexsys plant in Nitro in 1998 (Charleston Daily Mail 1998). Almost 550 Nitro High School students and students attending after-school programs at Cross Lanes Elementary and Nitro Elementary sheltered in place from 2:30 p.m. until about 3:20 p.m. "Basically, we shut the place down," said Nitro High School Principal Paul McClanahan. School officials shut off all vents, taped the doors and talked with students about what was happening.

- Kanawha County officials recommended sheltering again in October 1999 in response to a chemical plant release of what turned out to be phosgene (Charleston Daily Mail 1999). No injuries were reported outside the plant boundary. The County Emergency Director expressed a strong preference for sheltering in this type of event. He said that regardless of what chemical leaks from the plant, the best response for nearby residents is to shelter in place, and that if residents run to their cars and attempt to evacuate, they will face the chemical cloud in a traffic jam where their protection is less.

- On March 25, 1999, an explosion and fire at a Chevron refinery on the edge of San Francisco Bay sent a pillar of black smoke into the air, prompting authorities to warn area residents to remain indoors. Neighbors of the refinery were told to seal their homes as well as they could and SIP. But according to the newspaper article, "despite those orders, streets were busy, with children playing and people waiting for buses." A number of people reported to area hospitals complaining of breathing problems (Warren 1999). At J.O. Ford Elementary School, SIP procedures were to keep the children in classrooms until the emergency passed. Parents arriving to pick up their children were directed to the auditorium to wait, but most came to classrooms to pick up their children and go home (Hatfield et al. 1999).

- Shelter-in-place was ordered for a community in Scary, WY, following a train crash involving hazardous materials and a smoky fire. The stopped train blocked the only road to one neighborhood such that there was no automobile access or exit. Nonetheless a number of people evacuated the area on foot by 
crawling under the stopped train. The SIP order was left in place overnight (Newsday 1997).

\subsection{ANALYSIS}

The guidance documents and scholarly works generally took the simplistic approach to the issue of terminating SIP. You leave, or ventilate a shelter when the outside concentration is less than the inside concentration to maximize dose reduction from SIP. The chief problem is that there is not a practical method of determining when the outside concentration is lower than the indoor concentration. The closest approach is in the EPA radiological incident guidance, which recommends that SIP not be used when the hazard duration is expected to exceed the average time for two air changes in affected structures. $^{20}$

Scholarly research reports also have seldom directly addressed decision criteria for terminating SIP. Some important technical groundwork has been laid through examination of air infiltration into structures. A range of air infiltration rates for typical housing stock has been established. These numbers then can be used to calculate concentration time-profiles for indoor and outdoor conditions for various types of releases and weather conditions. High winds and large indoor/outdoor temperature contrasts tend to accelerate infiltration. However, note that high winds also tend to dilute a toxic agent plume.

Another important technical foundation for decision making is the relationship between health effects and concentration of the harmful agent. Studies have shown that for many toxic chemicals, this relationship is non-linear, i.e., the toxic effect is related more to peak concentrations than to cumulative dosage. This is not considered in some of the literature that was reviewed for this report. This is significant for assessing the value of SIP because sheltering tends to flatten concentration "spikes." Thus sheltering may produce a health benefit even where the total dose over time is equal indoors and out.

The experts agree that protection is maximized if SIP is begun prior to plume arrival and terminated when outdoor concentrations drop below indoor concentrations. However, they appear to be divided on the issue of whether substantial protection is obtained if the sheltering exceeds the optimal time period. Indeed there appears to be some disagreement among the experts on the general advisability of SIP as a protective action against chemical hazards. Compare Dr. Rogers' statement at the 1995 NICS conference, "if in doubt, move them out," with Dr. Wilson's statement in a 1990 conference paper, "in most cases it is better to shelter indoors rather than attempt an evacuation while a toxic release event is in progress."

\footnotetext{
${ }^{20}$ However, direct application of this criterion to a chemical agent hazard is problematic because, among other things, radiation exposure is generally assumed to have a linear biological-response curve, whereas chemical exposures generally do not.
} 
A number of scholarly publications and advisory documents address the decision to shelter or evacuate. Although not directly within the scope of this paper, considerations behind that decision may indirectly affect the decision to terminate sheltering as well. There is a broad consensus on the following general, common-sense principles:

- Evacuation is the preferred alternative if it can be accomplished prior to arrival of the hazard.

- Evacuation is the preferred alternative if the released material is flammable or there is a risk of explosion. ${ }^{21}$

- SIP is the preferred alternative if evacuation is impossible (e.g., evacuation routes are blocked) and sometimes for populations that are difficult to evacuate (e.g., hospital patients).

- SIP is generally favored for short-duration releases and disfavored for longduration releases.

- $\quad$ SIP is favored where relatively tight shelter is available and disfavored where shelters are relatively leaky.

Advice is scant, however, as to how to weigh the last three factors or how to make a decision under conditions of uncertainty.

Once the determination to terminate SIP is made, what little literature is available is divided on whether to simply ventilate, abandon, or abandon and then evacuate to a known safe area. In many cases, when specific guidance is provided, it is not supported by any analysis and therefore is not definitive. In some cases, an interpretation of the guidance on egress from SIP suggests that the specific action that is taken depends on the potential for aerosol deposition of the agent involved. For example, when persistent agent releases are discussed, the guidance suggests that the shelter should be ventilated once the plume has passed, even if the shelter is not vacated because of the possibility of outside surface contamination. Additionally, for non-persistent agents, abandoning or abandoning and then evacuating to a known safe area is generally suggested, though with some consideration for the risk of residual vapor in the air after the plume has passed (e.g., in the wake of a building or in a depression in the terrain).

Two other points come out of the scholarly literature, relating to human behavioral aspects of emergency response. Both point to the importance of public education and information campaigns in implementing SIP. First, several experts alluded to a tendency on the part of the public to want to evacuate rather than SIP. (This appears to be borne out by reported cases; see below.) Public education is cited as an important factor in compliance with instructions to SIP. Secondly, the length of time that it takes for

${ }^{21}$ Chemical warfare agent vapors (nerve and blister) are neither explosive nor flammable at the maximum concentrations expected off-post. 
the public to implement instruction to complete SIP is dependent on the amount of education and practice they have had. As reported in the ATSDR paper, models and studies of actual events indicate that an unpracticed community may take 60 minutes from the time of a release to implement sheltering, whereas a community that has "planned, prepared, and practiced" will need only 25 to 30 minutes. If it takes longer to obtain protective shelter than it would to evacuate, SIP is not an attractive alternative.

Analysis of instances of SIP reported in newspaper accounts indicates that it has been used, both for the general public and for school children, although apparently not very often. Only a handful (less than 10) of such instances were found over the last four years. (However, no search for reports of evacuation was done for comparison.) Use of SIP appears to be concentrated in a few areas, such as the Kanawha valley in West Virginia and the Mississippi river area between Baton Rouge and New Orleans, Louisiana, that have heavy concentrations of chemical industrial facilities. However, perhaps that pattern indicates that SIP is favored by those response agencies most experienced in these matters.

Reading the newspaper accounts of actual events, one gets a sense that the officials involved were fairly conservative in terms of sounding the all clear after a SIP instruction. That is, they did not appear to be especially concerned with air infiltration setting a limit on the useful life of the available shelter. Generally the SIP instruction was left in place either until the hazard was terminated or until further investigation determined that the odor or smoke was non-hazardous. In one case the SIP instruction was left "on" overnight. One also gets the sense that compliance with these SIP orders was not absolute: there are reports of people coming to pick up their children at school, or evacuating, or simply walking about unconcernedly, even for releases in which other people went to the hospital complaining of breathing problems. That behavior may relate to the fact that the releases in question were easily detectable by the human senses of smell and sight; people may have felt that they could evaluate the danger themselves. 


\section{SECTION 5: CONCLUSIONS}

\subsection{No "Off-the-Shelf” Methods Available to Terminate SIP}

As discussed throughout this report, SIP is a valuable protective action strategy. In order to make this strategy as effective as possible, it is important to terminate SIP at an appropriate time and in an appropriate way. Therefore, this literature search focused specifically on how to decide when a sheltered population should ventilate or exit from a temporary shelter to minimize exposure to agent vapors that infiltrate shelters during the passage of the vapor plume, and if they should subsequently relocate to a known safe area. $^{22}$

Army literature and CSEPP guidance identifies SIP as an important protective action option in the event of a chemical accident, acknowledges the importance of the shelter infiltration issue, and calls for a systematic approach in determining an SIP termination strategy. However, these documents do not directly address what the exit strategy should be, and other programmatic models are even less specific than the Army and CSEPP guidance.

After analyzing the results of the literature search, it was concluded that no "offthe-shelf" decision making methods are available for determining when and how sheltered populations should act to minimize exposure to accumulations of hazardous vapors within the shelter.

\subsection{Possible Components of Methods to Terminate SIP}

Given the accuracy of existing models and the lack of capability to monitor in a timely fashion, there is probably no practical solution to this problem that is $100 \%$ reliable at this time. However, the literature search led to information about many of the variables that need to be considered in a successful strategy to terminate SIP. These include dispersion models (e.g., D2PC, PARDOS, D2-Puff), guidance on dispersion modeling and source term characterization, shelter protection factors, event characteristics, meteorology, type of release, potential for aerosol deposition, shelter ventilation times, agent toxicology, alert and notification requirements, threshold levels for exposure, and public education and training. Monitoring solutions to SIP termination decision-making were not in evidence in the literature, though source term monitoring might prove useful.

The methodology for determining PARs in the PADRE model will also be studied during Task 2. This question is of interest because PADRE considers numerous relevant variables in selecting between an evacuation and a shelter-in-place PAR, and the model could potentially be modified to address the temporary SIP concept. Similarly, the

\footnotetext{
${ }^{22}$ Some of the literature reviewed during this search ignored vapor infiltration of shelters as a factor in assessing the efficacy of sheltering as a protective action strategy. These sources were discounted as irrelevant to this inquiry, because vapor infiltration is absolutely a factor.
} 
methodology used in the development of the IEM guidebook for ANCA will also be considered because it considers many variables that are relevant to SIP.

Almost all of the literature cited in this report that pertains to nerve agent is based on current toxicological information (i.e., linear biological response) and therefore must be considered with that limitation. Given the latest toxicological information that might soon be used by the Army (i.e., AEGLs), which account for the non-linearity of the biological response to some CWA, SIP can probably provide reasonable protection in some nerve agent releases of longer duration. Additional protection is provided because the indoor concentrations will be more constant versus the fluctuating peaks and valleys of the outside concentrations. Similarly, remaining in a shelter beyond the "optimal" time to exit is apparently better than not sheltering at all. While indefinite SIP following a CWA release might give nearly the same dosage as staying outdoors, the lower indoor concentrations over a longer time will result in a lower toxic effect. This information will be considered carefully in Task 2 . It is expected that SIP termination decision-making methods will apply to both current standards and CWA AEGLs.

\subsection{Steps to Terminating SIP}

In a perfect world, emergency responders would always be ready to detect and analyze a chemical accident. Decision-makers and their support staff would be trained and equipped to select and broadcast the best protective action directions. The population at risk would understand and be prepared to execute temporary SIP effectively if that is the recommended protective action. Thus, if a chemical accident should occur, this enhanced readiness posture would allow emergency responders to promptly detect the event and to quickly consider the variables that determine protective action options. In turn, decision-makers could quickly select the best choices of protection from a matrix and alert and notify the affected population accordingly. Most importantly, an educated and trained population could then effectively execute the protective action in minimal time and with confidence in the actions taken.

Several key steps need to occur during the emergency response process to execute temporary SIP effectively. Most of these steps are common to other protection strategies but are critical to temporary SIP termination options.

- Characteristics of the event (e.g., mode, quantity, duration of release, and potential for aerosol deposition) need to be determined by the Army very quickly and updated continuously. Details such as results of monitoring at and near the site of the release, and eye witness reports from the scene, must be collected promptly and analyzed immediately for public health and safety implications. If initial responses are based on assumptions from the work plan MCE for a chemical operation, the actual mode, quantity, and duration of the release needs to be revised as soon as facts are known, lest the timing of the termination of temporary SIP be skewed. 
- Characteristics of the plume (e.g., concentration, direction, and rate of movement) need to be modeled, tracked, and displayed continuously by the Army. Criteria needed for decision making must be presented in near real time. Predictions of likely changes in plume characteristics should be made regularly, based on activities and events at the site and changing meteorology.

- Protection variables (e.g., shelter protection factors, ventilation times, detoxification rates, threshold exposure levels, and distance of the population from the source) need to be considered in relationship to one another, and to the characteristics of the plume. Much of this can be assessed before-hand, and covered in plans and agreements.

- PADs must be disseminated quickly and succinctly to the population at risk both on-post and off-post. If persons are directed to SIP with the expectation that subsequent ventilation or relocation is essential, they should be told to anticipate this action, and then be given the direction to terminate SIP in a timely fashion.

- The target population must establish their shelters quickly and use them effectively, if the temporary SIP strategy is to succeed. SIP kits need to be as simple as possible so protection can be obtained without delay. There were no CSEPP guidelines or standards on the time needed or expected to take to shelter a population found during the literature search.

\subsection{Task 2 Work on Methods to Decide When and How to Terminate SIP}

During Task 2 of this project, ANL intends to integrate the results of this literature search with new ideas to produce a coherent concept to determine when and how to terminate SIP, along with an appropriate implementing methodology. The objective is to make temporary SIP a credible, defensible protective action strategy.

Since the CSEPP guidance favors decision tables or matrices to display decision making processes, (CSEPP 1996, pp. D-6, D-7, and N-2-8), ANL will consider formatting the product of Task 2 as a generic decision matrix to terminate SIP. The matrix would ultimately need to be adjusted to site specific circumstances by zone or facility, and should account for the major variables that influence when and how to terminate SIP in that zone or facility. The major variables include:

- Reasons why a population would SIP. This information would link the decision matrix for terminating SIP with the decision matrix for deciding to SIP initially. A single comprehensive list of reasons why a population would SIP was not found in the literature, so one needs to be constructed.

- Choice of tools to use to decide when and how to terminate SIP, and how these tools should be used. This includes information needed to use the tools effectively, and how that information might be acquired. 
- Options upon termination of SIP, and mechanisms for communicating these directions to persons sheltered-in-place.

- Assumptions about shelter protection factors, shelter ventilation times, agent toxicology, threshold levels for exposure, and public education and training.

The decision matrix should provide a basis for decision makers to determine the time to terminate SIP for each zone or facility where persons are sheltered-in-place, and the proper action upon termination. The outcome of the matrix should always lead to the avoidance of fatalities to the maximum extent practicable.

\subsubsection{Reasons Why a Population Would SIP}

The following list of reasons why a population would SIP was compiled from discussions in the CSEPP guidance, jurisdiction plans, and reports of CSEPP exercises. Upon reviewing this list, one could conclude that some persons will end up sheltered-inplace regardless of the PARs or PADs. This, in turn, suggests that decisions about when and how to terminate SIP will need to be made during any chemical accident classified as a community emergency.

- Response to a SIP PAD because they are within the "no deaths" arc within the hazard wedge, and it has been determined that there is not sufficient time for them to evacuate. This is the classic example of a population for which timely termination of temporary SIP is most critical.

- Response to a SIP PAD because they are within the hazard wedge but outside the "no deaths" arc, and it has been determined that there is not sufficient time for them to evacuate. This is another classic example of a population for which timely termination of temporary SIP is appropriate, though perhaps not as critical as a population within the "no deaths" arc.

- Response to a PAD to evacuate that cannot be executed because of a handicap or lack of transportation. These persons need to know about the risks associated with SIP and must be prepared to at least ventilate or exit from their shelters when instructed to do so. Perhaps an initial PAD to evacuate within a zone should include direction for persons who are handicapped or lack transportation to take temporary shelter immediately.

- Response to a SIP PAD because a delay in making or implementing a PAD to evacuate precluded a safe and timely evacuation. This could also include persons who did not learn about the initial PAD, and who sheltered-in-place in a structure that was already infiltrated with agent vapors. 
- Response to a SIP PAD because they are in a zone for which an automatic default PAD to SIP was made, despite an Army PAR to evacuate that zone. This is a questionable strategy if the reason for postponing evacuation was to obtain more information, such as from monitoring within the potentially affected zone. Persons who took temporary shelter might now have insufficient time to evacuate safely.

- Response to a SIP PAD that turns out to have been inappropriate--the PAD should have been to evacuate. This could result from inaccurate data about the duration of the plume, or human error in the event reporting, hazard analysis, PAR, PAD, or alert and notification sequence. In this case, the implications of the error must be assessed immediately, and a corrected protective action direction must be broadcast immediately if circumstances warrant. This broadcast could include direction to terminate SIP immediately.

- Response to a SIP PAD because they are within a zone touched by the hazard wedge, even though they are outside of the wedge. This population is not likely to be at risk. Their SIP is an artifact of the zone boundaries, but it creates a potentially very large sheltered-in-place population.

- Response to a SIP PAD made as a contingency, e.g., for a potential weather change, despite the absence of an Army PAR for this zone. Since this population is not at risk, there is no urgent reason to be concerned about the time they spend in shelters from the standpoint of vapor infiltration.

- Response to a SIP PAD that is the first step in a "phased evacuation." ${ }^{23}$

- A personal decision to SIP, contrary to a PAD to evacuate. Even though the literature shows that people are generally predisposed to evacuate rather than SIP, a few might intentionally SIP despite an evacuation directive (e.g., because of concern for pets, a misunderstanding of the PAD, or a lack of confidence in the authority that directed evacuation. These were mentioned as infrequent occurrences in news articles about mass evacuation of populations). Fewer people might SIP for these reasons if they were educated about vapor infiltration.

23 "Temporary SIP" should not be confused with "phased evacuation." The latter is an evacuation before the expected arrival of the plume that is done in phases to minimize traffic congestion, with populations taking temporary SIP while waiting their turn to evacuate. 


\subsubsection{Choice of Tools to Use to Decide When and How to Terminate SIP}

Following are the primary tools mentioned in the literature that apply to the decision on when and how to terminate SIP.

- Agreements and protocols concerning such matters as how much lead time is needed to act on a PAR to terminate SIP, and how much time is available to implement a PAD to terminate SIP.

- Non-conservative modeling to determine when the tail of the plume is expected to pass an individual shelter, or a point in a zone that is representative of the best time for a population within that zone to terminate SIP. The best point in a zone might be the geographical or population midpoint, or it might be the point that will avoid fatalities in the zone to the maximum extent practicable.

- Monitoring (air and surface) at or near the accident site to verify assumptions about the size and duration of the release, to enhance the results of modeling the plume.

- Real time atmospheric data from the best available sources.

- Eye-witness information about the conditions at the site of the release.

\subsubsection{Options Upon Termination of SIP}

Following are options mentioned in the literature for terminating SIP once the decision is made to do so.

- Return to normal activity with no restriction.

- Ventilate the shelter, unless exit or relocation is so urgent that time to do this is not available.

- Exit from the shelter and remain outside nearby until ventilation is complete. How to decide when shelter is adequately ventilated, inclement weather, and personal handicaps might complicate this option in some cases. The potential for aerosol deposition should be a minor consideration since it is a remote possibility, and not likely to be a safety factor at great distances from the source even if agent aerosol is generated by the event.

- Exit from the shelter and relocate to a place designated for medical screening or accounting for the sheltered population, as determined by decision makers. The preferred direction to relocate is away from the path of plume travel to avoid catching up with the plume, if it still exists. This might not be the primary evacuation route. 


\section{APPENDIX 1: POTENTIAL FOR BUILDUP OF HAZARDOUS VAPORS IN SHELTERS DURING THE PASSAGE OF A PLUME OF AIRBORNE HAZARDOUS MATERIAL}

The following information is derived mostly from Stay Indoors or Evacuate to Avoid Exposure to Toxic Gas?, Emergency Preparedness Digest, Proceedings of the Conference on In-Place Protection During Chemical Emergencies, and The Influence of Non-Linear Human Response to Toxic Gases on the Protection Afforded by Shelteringin-Place.

The potential for build-up of hazardous vapors in normal, enhanced and expedient shelters during the passage of a plume of airborne hazardous materials exists due to the exchange of air between the shelter with the exterior environment. In general, outside air enters or infiltrates these types of shelters through small leakage sites, such as cracks around windows and doors, as well as the gap between the basement foundation and building walls. Similarly, inside air typically exits or exfiltrates via the furnace flue, ventilation fans, and cracks near the ceiling level of the structure. The quantity of air that is exfiltrated is equal to quantity of air that infiltrates.

The air infiltration rate into a shelter is typically given in air changes per hour $(\mathrm{ACH})$, which is the infiltration flow rate (i.e., volume/time) divided by the active interior volume in the shelter (i.e., volume). The active interior volume of a shelter is the total volume less closets, sealed spaces, wall cavities, etc.

Natural convection within a shelter will tend to keep the air within the active volume well mixed. Therefore it is typically assumed that once outside air gets into a shelter it will rapidly become well mixed with the interior air.

Any shelter that exchanges unfiltered air with the exterior environment (this includes normal, enhanced and expedient shelters but not pressurized shelters) will receive some buildup of hazardous material if a hazardous vapor plume passes around the shelter. Tighter shelters (i.e., ones with lower air change rates) will allow less outside air and therefore less hazardous vapors to get inside than leakier shelters. Similarly, tighter shelters will serve to impede the exfiltratation of any hazardous agent that has built up inside the shelter.

Figure 1 below illustrates how air exchange rates effect indoor concentrations of chemical agent for shelters with different air exchange rates. An extremely leaky shelter would have an air exchange rate on the order of 5.0 ACH, while a tightly sealed shelter would have an air exchange rate on the order of $0.5 \mathrm{ACH}$. The concentrations indoors and outdoors are equal when the curve representing the outdoor concentration intersects with a curve representing a shelter with a particular ACH. At any point after this time, the concentration of agent inside the facility is greater than it is outside. If people remain inside a shelter after the plume has passed, then they will continue to receive hazardous dosages of agent. If a person never exits the shelter, he or she will receive approximately 
the same agent dosage (but not necessarily the same toxic effect) that would have been received had the person stood outside during the event.

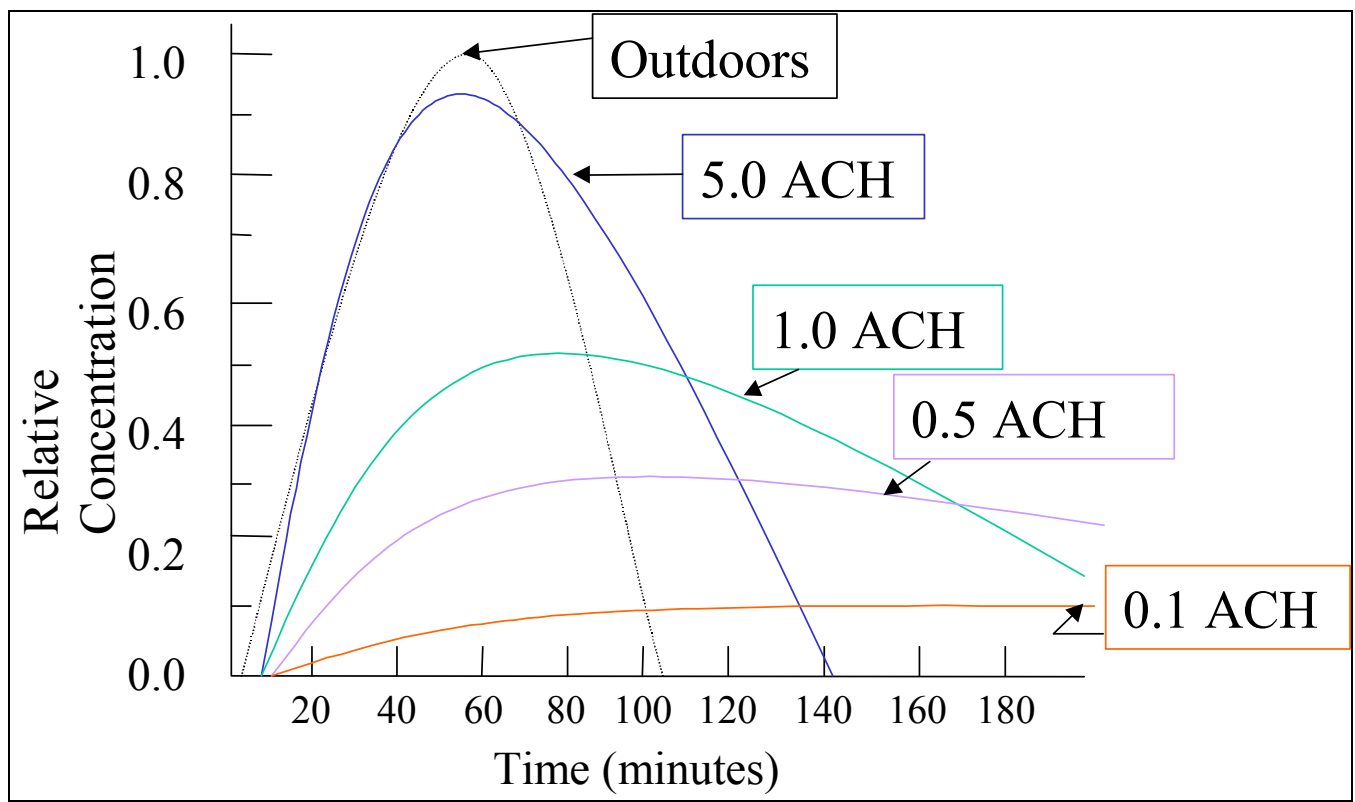

Figure 1: Relative Concentrations of Agent Over Time Outdoors and Inside Shelters with Varying ACH Rates.

The example outside concentrations shown in Figures 1 above represent the mean concentration that might be experienced for a given release. ${ }^{1}$ Real plumes tend to have concentrations that fluctuate significantly (i.e., peaks and valleys in the time history of the concentration) especially within the first mile from the point of release. For chemicals where the toxic effect is not linear, these fluctuations will result in a higher toxic effect than would be expected by just looking at the mean concentration, according to The Influence of Non-Linear Human Response to Toxic Gases on the Protection Afforded by Sheltering-in-Place. As compared to the mean concentrations, the peaks will tend to add significantly more toxic load than the valleys effectively take away because of the nonlinearity of the biological response. ${ }^{2}$

\footnotetext{
${ }^{1}$ Dispersion models, such as D2PC and D2-Puff, predict mean concentrations and not fluctuating concentrations.

${ }^{2}$ See paragraph 2.4 of this report.
} 


\section{APPENDIX 2}

\section{REFERENCES}

Advocate, The (Baton Rouge, La.), 2000, "Officials complain plant failed to report problem," Metro edition, News section, p. 5-B, Feb. 25.

Anniston Army Depot, 1999, ANAD CAIRA Plan, November.

Bearg, D.W., 1993, Indoor Air Quality and HVAC Systems, Lewis Publishers, p.115.

Blewett, W.K., Reeves, D.W., Arca, V.J., Fatkin, D.P., and Cannon, B.D., 1996, "Expedient Sheltering in Place: An Evaluation for the Stockpile Emergency Preparedness Program," ERDEC-TR-336, June.

Blewett, W.K., and V.J. Arca, 1999, "Experiments in Sheltering In Place: How Filtering Affects Protection Against Sarin And Mustard Vapor,” ECBC-TR-034, June.

Charleston Daily Mail (Charleston, West Virginia), 1998, "Flexsys plant fire causes alarm in Nitro - Shelter in place ordered after mishap at facility," News section, p. 1A, October 22.

Charleston Daily Mail (Charleston, West Virginia), 1999, "Different chemical reportedPlant manager says both substances make cloud," News section, p. 7A, October 19.

Copenhaver, E.D., Clevenger, W. F., Coomer, C. J. and Sorensen, J. H., 1995, Technical Planning and Evaluation Facilitator's Guide, ORNL/M-3184, Oak Ridge National Laboratory, Oak Ridge, Tennessee, March.

CSEPP, 1991, Policy Paper Number 1, Definition of Maximum Protection, May.

CSEPP, 1999a, The Exercise Policy and Guidance for the CSEPP, March 19.

CSEPP, 1996, Planning Guidance for the CSEPP, May 17.

CSEPP, 1999, The CSEPP Off-Post Monitoring Integrated Process Team [IPT] Report, January.

CSEPP, 2000a, Report of the Umatilla Community CSEPP Exercise 2000.

CSEPP, 2000b, Report of the Newport Community CSEPP Exercise 2000.

EPA: See U.S. Environmental Protection Agency. 
Glickman, T.S., and A.M. Ujihara, eds., 1989, Proceedings of the Conference on In-Place Protection during Chemical Emergencies (held November 30 - December 1, 1988, National Emergency Training Center, Emmitsburg, Md.), Resources for the Future, Inc., Center for Risk Management, Washington, D.C.

Hatfield, L.D., et al., 1999, "Safety audits demanded; Smoke from blast and blaze sends 350 to hospitals," San Francisco Examiner, second edition, News section, p. A-1, March 26.

IEM: See Innovative Emergency Management, Inc.

Innovative Emergency Management, Inc. and Myirski, M., 1993, Reference Manual: D2PC and Hazard Analysis.

Innovative Emergency Management, 1999a, Draft Student Manual: Protective Action Implementation: Sheltering and Evacuation, September.

Innovative Emergency Management, Inc., 1999b, Draft Student Manual: Sounding AllClear for Sheltered Personnel, September.

Innovative Emergency Management, Inc., 2000a, Alabama CSEPP Protective Action Recommendation Guidebook-All Counties, IEM Report No. IEM/TEC00-022, Feb.

Innovative Emergency Management, Inc., 2000b, Technical Addendum to Alabama CSEPP Protective Action Recommendation Guidebook, IEM Report No. IEM/TEC00023, Feb.

Janus, M., J. Widder, S. Golly, K. Ewing, and J. Barrett, 1998, CSEPP Chemical Detection Equipment Assessment, Vols. 1 and 2, U.S. Army Chemical and Biological Defense Command Chemical Stockpile Emergency Preparedness Program, April.

Mileti, D., 1999, Presentation at Protecting the Public: A Conference on Protective Actions During Chemical Emergencies, Concord, California, October.

Myirski, M., 2000, "Status: Risk AEGLs/Sheltering/PAR-PAD Matrix," presented at Clinton, Indiana, November.

Naegeli, W., PADRE_-Protective Action Dosage Reduction Estimator: Draft Users Manual, 1998, Oak Ridge National Laboratory and The University of Tennessee, Oak Ridge, Tennessee, August.

Newsday (Associated Press), 1997, "Hundreds flee toxic fumes / Flames follow train collision," Nassau and Suffolk Edition, News section, p. A14, June 9. 
National Institute for Chemical Studies (NICS), 1995, Proceedings from Protecting the Public: A Conference on Protective Actions during Chemical Emergencies, Charleston, West Virginia, September 20-21.

NICS, 1999, Proceedings from Protecting the Public '99: A National Conference on Protecting the Public During Chemical Emergencies, Concord, California, Oct. 4-5.

NRC: See U.S. Nuclear Regulatory Commission

Paddock et al., Argonne National Laboratory, unpublished information, 1994.

Prater, E., S. Stage, and J. Weltman, 1998, "D2-Puff Model Technical Manual," IEM/TEC98-024, IEM, November.

Rogers, G.O., A.P. Watson, J.H. Sorensen, R.D. Sharp, and S.A. Carnes, 1990, Evaluating Protective Actions for Chemical Agent Emergencies, ORNL-6615, Oak Ridge National Laboratory, Oak Ridge, Tennessee, April.

Rogers, G.O., and R.D. Sharp, 1990, Protective Action Evaluator for Chemical Emergencies: A User's Manual (MS-DOS Version 1.0), ORNL/TM-11594, Oak Ridge National Laboratory, Oak Ridge, Tennessee, October.

Sorensen, J. H., A. Watson, and B. Shumpert, 1995, Presentation on Shelter-In-Place as a Protective Action From Inhalation Exposure, Oak Ridge National Laboratory, Oak Ridge, Tennessee, January.

SSI Services, 1998, Technical Report, Development of a Default Protective Action Decision Strategy for the Kentucky Chemical Stockpile Emergency Preparedness Program, January.

St. Clair County Emergency Management Agency, (undated), Emergency Information Guide.

USADAC: See U.S. Army Defense Ammunition Center.

U.S. Army, 1991, Chemical Accident or Incident Response and Assistance Operations, DA PAM 50-6, May 17.

U.S. Army Defense Ammunition Center, 1995, "Chemical Hazard Prediction for Decision Makers," handout for course AMMO-T-21, October.

U.S. Army Defense Ammunition Center, 1999a, "Chemical Hazard Prediction for Decision Makers," handout for course AMMO-T-22, September.

U.S. Army Defense Ammunition Center, 1999b, Chemical Hazard Prediction," handout for course AMMO-T-23, August. 
U.S. Department of Health and Human Services, undated, "Shelter-in-Place: Planning and Implementation," Agency for Toxic Substances and Disease Registry (ATSDR).

U.S. Department of Transportation Research and Special Programs Administration, 2000, North American Emergency Response Guidebook, available at http://hazmat.dot.gov/gydebook.htm .

U.S. Environmental Protection Agency, 1992, Manual of Protective Action Guides and Protective Actions for Nuclear Incidents, EPA-400-R-92-001, May.

U.S. Environmental Protection Agency National Advisory Committee, 2000, Acute Exposure Guideline Levels (AEGLs) for Sulfur Mustard (Agent HD), CAS Reg. No 50560-2, Draft, January.

U.S. Nuclear Regulatory Commission, 1996, Response Technical Manual 96, NUREG/BR-0150, Vol. 1, Rev. 4, March.

U.S. Nuclear Regulatory Commission/Federal Emergency Management Agency, 1980, Criteria for Preparation and Evaluation of Radiological Emergency Response Plans and Preparedness in Support of Nuclear Power Plants, NUREG-0654/FEMA-REP-1, Revision 1.

U.S. Nuclear Regulatory Commission/Federal Emergency Management Agency, 1996, Criteria for Protective Action Recommendations for Severe Accidents, Draft Report for Interim Use and Comment, NUREG-0654 / FEMA-REP-1, Rev. 1, Supp. 3, July.

Umatilla Chemical Depot, 2000, Umatilla Chemical Depot CAIRA Plan, April 3.

Warren, M., 1999, "Explosion at Chevron facility starts huge fire on San Francisco Bay," Associated Press State and Local Wire, March 26.

Wilson, D.J., 1987. "Stay Indoors or Evacuate to Avoid Exposure to Toxic Gas?" Emergency Preparedness Digest, Vol. 14 No. 1, January-March.

Wilson, D.J., and B.W. Zelt, 1990, “The Influence of Non-Linear Human Response to Toxic Gases on the Protection Afforded by Sheltering-in-Place," presented at Organization for Economic Cooperation and Development and the United Nations Environment Programme (OECD/UNEP) Workshop on Emergency Preparedness and Response, Boston, Mass., May 7-10.

Wilson, D.J., and B. Morrison, 2000, “Ordering Shelter or Evacuation During an Outdoor Toxic Gas Release Incident: The C.A.F.C. Decision Flow Chart," presented at the Annual Meeting of the Canadian Association of Fire Chiefs, Montreal, Canada, August 13-18. 
Wu, D.L., and D.W. Sloop, 1986, "A Package of Transport and Diffusion Models for Biological and Toxin Agents," US Army Chemical Research, Development, and Engineering Center, CRDEC-TR-86034, June. 


\section{APPENDIX 3}

\section{BIBLIOGRAPHY}

Aberdeen Proving Ground CAIRA Plan, 7 March 2000.

Advocate, The (Baton Rouge, La.), Officials complain plant failed to report problem, Metro edition, News section, p. 5-B, February 25, 2000.

ALOHA User Guide, available at http://response.restoration.noaa.gov/cameo/decision/ keyindex.html.

Anniston Army Depot, ANAD CAIRA Plan, Nov. 1999.

Baskett, R.L., Evaluation of an emergency response model with instantaneous air concentrations during stable conditions: Revision 1.

Bearg, D.W., Indoor Air Quality and HVAC Systems, Lewis Publishers, 1993.

Blewett, W.K., and Arca, V.J., Experiments in Sheltering in Place: How Filtering Affects Protection Against Sarin and Mustard Vapor, ECBC-TR-034, June 1999.

Blewett, W.K., Reeves, D.W., Arca, V.J., Fatkin, D.P., and Cannon, B.D., Expedient Sheltering in Place: An Evaluation for the Stockpile Emergency Preparedness Program, ERDEC-TR-336, June 1996.

Blue Grass Army Depot CAIRA Plan, 30 June 2000.

Brown, M.J., and Streit, G.E., Emergency Responders' "Rules-of-Thumb" for Air Toxics Releases in Urban Environments, LA-UR-98-4539.

CAMEO User Guide, available at http://www.epa.gov/ceppo/cameo/cameo.htm.

Carnes, S.A., et al., Emergency Response Concept Plan for Anniston Army Depot and Vicinity, ORNL/TM-11093, Martin Marietta Energy Systems, Inc., Oak Ridge National Laboratory, Oak Ridge, Tennessee, 1989.

Carnes, S.A., Emergency response concept plan for Lexington-Blue Grass Army Depot and vicinity, ORNL/TM-11099.

Carnes, S.A., Emergency response concept plan for Newport Army Ammunition Plant and vicinity, ORNL/TM-11095.

Carnes, S.A., Emergency response concept plan for Pine Bluff Arsenal and vicinity, ORNL/TM-11092.

Carnes, S.A., Emergency response concept plan for Pueblo Depot Activity and vicinity, ORNL/TM-11098.

Carnes, S.A., Emergency response concept plan for Toole Army Depot and vicinity, ORNL/TM-11094.

Carnes, S.A., Emergency response concept plan for Umatilla Army Depot and vicinity, ORNL/TM-11097.

Carnes, S.A., Site-specific emergency response concept plans for the Chemical Stockpile Disposal Program: A comparative summary, ORNL/TM-11357, 1989. 
Casal, Cuchi, and Casal, Sheltering as a protective measure against virus spread, Journal of Hazardous Materials A68 (1999) 179-189.

Cassidy, J.K., Protective Action Decision-Making for Chemical Emergencies, Crossroads, National Safety Council, October 20, 2000. Available at http://www.crossroads.nsc.org/articleTemplate.cfm?id=91\&subjectID=2 .

Charleston Daily Mail (Charleston, W.Va.), Flexsys plant fire causes alarm in Nitro Shelter in place ordered after mishap at facility, News section, p. 1A, October 22, 1998.

Charleston Daily Mail (Charleston, W.Va.), Different chemical reported - Plant manager says both substances make cloud, News section, p. 7A, October 19, 1999.

Chester, C.V., Technical Options for Protecting Civilians from Toxic Vapors and Gases, ORNL/TM-10423, May 1988.

County Emergency Response Plans. Samples reviewed by author Yantosik.

Coomer, C. J., and Sorensen, J. H., Technical Planning and Evaluation Student Workbook, version 2.0, Oak Ridge National Laboratory, Oak Ridge, Tennessee, December 1997.

Copenhaver, E. D., Clevenger, W. F., Coomer, C. J. and Sorensen, J. H., Technical Planning and Evaluation Facilitator's Guide, ORNL/M-3184, Oak Ridge National Laboratory, Oak Ridge, Tennessee, March 1995.

Criteria for Preparation and Evaluation of Radiological Emergency Response Plans and Preparedness in Support of Nuclear Power Plants, Nuclear Regulatory Commission and Federal Emergency Management Agency, NUREG-0654 / FEMA-REP-1, Rev. 1, 1980.

Criteria for Protective Action Recommendations for Severe Accidents, Draft Report for Interim Use and Comment, Nuclear Regulatory Commission and Federal Emergency Management Agency, NUREG-0654 / FEMA-REP-1, Rev. 1, Supp. 3, July 1996.

CSEPP Calendars for 2000. Samples reviewed by author Yantosik.

CSEPP Memorandum of Agreement and Memorandum of Understanding (MOA/MOU) Guide, Argonne National Laboratory, May 1999.

CSEPP Off-Post Monitoring Integrated Process Team Report, January 1999. Available at http://csepp.apgea.army.mil/biblio/trp/report.pdf .

CSEPP Policy Paper \#1, Definition of Maximum Protection, May 1991.

CSEPP Policy Paper \#2, Environmental Sampling to Determine Agent Contamination, 20 September 1993.

CSEPP Policy Paper \#7, Interim Policy Regarding Off Post Meteorological Towers for CSEPP, 26 March 1993. Available at http://csepp.apgea.army.mil/ bibliography.

CSEPP Public Information Brochures (undated). Samples reviewed by authors Yantosik and Lerner. 
Davis, D.S., et al., Accidental Releases of Air Toxics: Prevention, Control, and Mitigation, Noyes Data Corp., Park Ridge, N.J., 1989.

Department of the Army Memorandum Concerning Maximum Credible Events (MCE) for Daily Chemical Operations, 30 April 1997.

Deseret Chemical Depot CAIRA Plan, April 2000.

Emergency Response Planning Guidelines, Set 7: Allyl Chloride, Carbon Disulfide, Chorotrifluoroethylene, Isobutyronitrile, Titanium Tetrachloride, American Industrial Hygiene Association.

Excerpts EMIS Ver 3.1, U.S. Army Emergency Management Information System, Defense Ammunition Center, 1 November 1998.

Exercise Policy and Guidance for the CSEPP, 19 Mar 1999.

Fast, J.D., O'Steen, B.L., and Addis, R.P., Development of an advanced atmospheric/transport model for emergency response purposes, Westinghouse Savannah River Co., Aiken, S.C., 12 July 1992.

Fletcher, B., and Saunders, C.J., Air change rates in stationary and moving motor vehicles, Journal of Hazardous Materials 38 (1994) 243-256.

Glickman, T.S., and Ujihara, A.M., Deciding between in-place protection and evacuation in toxic vapor cloud emergencies, Journal of Hazardous Materials 23 (1990) 57-72.

Glickman, T.S., and Ujihara, A.M., eds., Proceedings of the Conference on In-Place Protection During Chemical Emergencies, Nov. 30-Dec. 1, 1988, National Emergency Training Center, Emmitsburg, Md., Center for Risk Management, Resources for the Future, Washington, D.C., 1989.

Hatfield, L.D., et al., Safety audits demanded; Smoke from blast and blaze sends 350 to hospitals, San Francisco Examiner, second edition, News section, p. A-1, March 26, 1999.

Herzenberg, C., et al., Recovery from a Chemical Weapons Accident or Incident: A Concept Paper on Planning, ANL/DIS-TM-14, April 1994.

Hewett, P.L. Jr., Mitrani, J.E., Absil-Mills, M.J.G., Tallarovic, P., and Molsen, J, An analysis of chemical stockpile emergency preparedness program exercise results: volume 1: the CSEPP exercise results database, ANL/DIS/TM-53, Vol. 1, June 1998.

Hilderman, T.L., Hrudey, S.E., and Wilson, D.J., A model for effective toxic load from fluctuating gas concentrations, Journal of Hazardous Materials A64 (1999) 115-134.

Holmes, J.M., and Byers, C.H., Countermeasures to Hazardous Chemicals, ORNL-6492, April 1989, pp. 171-174.

Hosty, Capt. J.W., Evacuation vs. Sheltering-Reducing human exposure during dangerous goods releases, Hazardous Materials Management, August/September 1995, available at http://www.hazmatmag.com/library/ docs/as95/as95017.html . 
IE Information Notice No. 83-28: Criteria for Protective Action Recommendations for General Emergencies, U.S. Nuclear Regulatory Commission, Office of Inspection and Enforcement, May 4, 1983. Available at http://www.nrc.gov/NRC/GENACT/GC/IN/1983/in83028.txt .

IEM, Inc., Alabama CSEPP Protective Action Recommendation Guidebook-All Counties, Report No. IEM/TEC00-022, February 2000.

IEM, Inc., Technical Addendum to Alabama CSEPP Protective Action Recommendation Guidebook, Report No. IEM/TEC00-023.

IEM, Inc., Draft Student Manual: Protective Action Implementation: Sheltering and Evacuation, September 1999.

IEM, Inc., Draft Student Manual: Sounding All-Clear for Sheltered Personnel, September 1999.

IEM, Inc. and Myirski, M., Reference Manual: D2PC and Hazard Analysis, August. 1993.

Janus, M., Widder, J., Golly, S., Ewing, K., and Barrett, J., CSEPP Chemical Detection Equipment Assessment, Vol. 1 and 2, U.S. Army Chemical and Biological Defense Command Chemical Stockpile Emergency Preparedness Program, April 1998.

Karlsson, E., and Huber, U., Influence of desorption on the indoor concentration of toxic gases, Journal of Hazardous Materials 49 (1996) 15-27.

Karlsson, E., Indoor deposition reducing the effect of toxic gas clouds in ordinary buildings, Journal of Hazardous Materials 38 (1994) 313-327.

Kletz, T.A., What went wrong? Case histories of process plant disasters. Gulf Publishing Co., Houston, Texas, 1998.

Leffingwell, S., correspondence during 1992 between Dr. Sanford Leffingwell from the CDC and the U.S. Army Chemical Research, Development, and Engineering Center (CRDEC).

Lindell, M.K., An overview of protective action decision-making for a nuclear power plant emergency, Journal of Hazardous Materials 75 (2000) 113-129.

Lombardi, D.A., Morris, M., and Watson, A.P., Using Air Dispersion Modeling as a Key Tool for Reentry Decision-Making Following an Accidental Release of Chemical Warfare Agent, Paper No. 93-TP-26B.04 in Proceedings of Air and Waste Management Association, June 14-18, 1993, Denver, Colorado, Vol. 1, 1993.

McKenna, T.J., Protective action recommendations based upon plant conditions, Journal of Hazardous Materials 75 (2000) 145-164.

Mileti, Dennis, Presentation at Protecting the Public: A conference on Protective Actions During Chemical Emergencies, Concord, California 1999.

Myirski, M., Shelter-In-Place slide presentation delivered at CSEPP National Conference, Little Rock, Arkansas, July 2000. 
Myirski, M., Status: Risk AEGLs/Sheltering/PAR-PAD Matrix, presented at Clinton, Indiana, November 2000.

Naegeli, W., PADRE_-Protective Action Dosage Reduction Estimator: Draft Users Manual, Oak Ridge National Laboratory and The University of Tennessee, Oak Ridge, Tennessee, August, 1998.

Newport Chemical Depot CAIRA Plan, 1 October 1999.

Newsday (Associated Press), Hundreds flee toxic fumes / Flames follow train collision, Nassau and Suffolk Edition, News section, p. A14, June 9, 1997.

Newsom, D., et al., Emergency response concept plan for the Chemical Stockpile Emergency Preparedness Program, rev. 1, vol. 1: emergency planning guide for the Anniston chemical activity CSEPP site, ANL/DIS/TM-48.

Newsom, D., et al., Emergency response concept plan for the Chemical Stockpile Emergency Preparedness Program, rev. 1, vol. 2: emergency planning guide for the Blue Grass chemical activity CSEPP site, ANL/DIS/TM-49.

Newsom, D., et al., Emergency response concept plan for the Chemical Stockpile Emergency Preparedness Program, rev. 1, vol. 4: emergency planning guide for the Edgewood chemical activity CSEPP site, ANL/DIS/TM-50.

Newsom, D., et al., Emergency response concept plan for the Chemical Stockpile Emergency Preparedness Program, rev. 1, vol. 5: emergency planning guide for the Newport Chemical Depot CSEPP site, ANL/DIS/TM-42.

O’Reilly, J.T., Emergency Response to Chemical Accidents (Planning and Coordinating Solutions), McGraw-Hill.

Paddock et al., Argonne National Laboratory, unpublished information, 1994.

PADRE 2.2 User Manual (on-line help file), Lockheed Martin Energy Research Corporation and the University of Tennessee, 1998.

Pine Bluff Arsenal CAIRA Plan, 14 February 2000.

Planning Guidance for the CSEPP, May 17, 1996.

Prater, E., et al. Indoor Dispersion Models for Evaluating Sheltering as a Protective Action, IEM/TEC99-040, Innovative Emergency Management, Inc., Baton Rouge, La., June 1999.

Prater, E., S. Stage, and J. Weltman, D2-Puff Model Technical Manual, IEM/TEC98024, IEM, November 1998.

Prescripted Siren System and Tone Alert Radio System messages. Samples reviewed by author Yantosik.

Proceedings from Protecting the Public: A Conference on Protective Actions During Chemical Emergencies. National Institute for Chemical Studies (NICS), Charleston, West Virginia., September 20-21, 1995.

Proceedings from Protecting the Public '99: A National Conference on Protecting the Public During Chemical Emergencies, Oct. 4-5, 1999, Concord, CA. NICS, Charleston, West Virginia 1999. 
Protecting the Public in a Hazardous Material Emergency, final project report, National Institute for Chemical Studies, Charleston, West Virginia, December 1988.

Protecting the Public in a Hazardous Material Emergency, initial project report, technical support appendices, National Institute for Chemical Studies, Charleston, West Virginia, September 1988.

Pruvost, N.L., ANS-8.23: Criticality accident emergency planning and response, Los Alamos National Laboratory, 24 June 1991.

Public Information materials for CSEP Program. Samples reviewed by author Yantosik.

Report of the Newport Community CSEPP Exercise 2000.

Report of the Pine Bluff Community CSEPP Exercise 2000.

Report of the Tooele Community CSEPP Exercise 2000.

Report of the Umatilla Community CSEPP Exercise 2000.

Rogers, G.O., 1996, Determining the Effectiveness of In-place Protection During Chemical Emergencies, Federal Emergency Management Agency, Region VI, Hazardous Materials Emergency Response Workshop, September 2426, 1996, Little Rock, Arkansas. Online presentation. Available at http://taz.tamu.edu/ rogers/CESPP\%20Presentation/index.htm .

Rogers, G.O., and Sharp, R.D., Protective Action Evaluator for Chemical Emergencies: A User's Manual (MS-DOS Version 1.0), ORNL/TM-11594, Oak Ridge National Laboratory, Oak Ridge, Tennessee, October 1990.

Rogers, G.O., and Sorensen, J.H., Adoption of emergency planning practices for chemical hazards in the United States, Journal of Hazardous Materials 27 (1991) 3-26.

Rogers, G.O., et al., Evaluating protective actions for chemical agent emergencies, ORNL/TM-6615.

Rogers, G.O., Sorensen, J.H., Long, J.F. Jr., and Fisher, D.F., Emergency planning for chemical agent releases, Environ. Prof., 11 (1989) 396-408.

Rogers, G.O., Watson, A.P., Sorensen, J.H., Sharp, R.D., and Carnes, S.A., Evaluating Protective Actions for Chemical Agent Emergencies, ORNL-6615, Oak Ridge National Laboratory, Oak Ridge, Tennessee, April 1990. Available at http://cseppweb-emc.ornl.gov/CSEPPPublications.html .

Rogers, G.O., The timing of emergency decisions: Modelling decisions by community officials during chemical accidents, Journal of Hazardous Materials 37 (1994) 353-373.

St. Clair County Emergency Management Agency, Emergency Information Guide (undated).

Shelter-in-Place: Planning and Implementation, Agency for Toxic Substances and Disease Registry, U.S. Department of Health and Human Services (approximately 1996). 
Sims, J., Advances in real-time technology assessment and emergency response: Close-in atmospheric dispersion modeling and exposure estimation. Lawrence Livermore National Laboratory, 1992.

Sorensen, J.H., Evacuation Due to Off-Site Releases from Chemical Accidents: Experience from 1980 to 1984, Journal of Hazardous Materials 14 (1987).

Sorensen, J.H., and Carnes, S., An approach for deriving emergency planning zones for chemical munitions emergencies, Journal of Hazardous Materials 30 (1992) 223-242.

Sorensen, J. H., Watson, A., and Shumpert, B., Presentation on Shelter-In-Place as a Protective Action From Inhalation Exposure, Oak Ridge National Laboratory, Oak Ridge, Tennessee, January 1995.

SSI Services, Technical Report, Development of a Default Protective Action Decision Strategy for the Kentucky Chemical Stockpile Emergency Preparedness Program, January 1998.

Thompson, P.G., Coomer, C.J., Shumpert, B., Sorensen, J.H., and Copenhaver, E.D., An Introduction to Protective Action Decision Making, videotape produced by the Emergency Management Center at ORNL, videotape \#1377-A (described at http://emc.ornl.gov/EMC/ProductTechVideo.html).

U.S. Army Materiel Command Chemical Service Response Force Plan (AMC-CSRFP), 21 July 1997.

U.S. Army, DA PAM 50-6, Chemical Accident/Incident Response Assistance Operations, May 1991.

U.S. Army Defense Ammunition Center, Chemical Hazard Prediction for Decision Makers, handout for course AMMO-T-21, Oct. 1995.

U.S. Army Defense Ammunition Center, Chemical Hazard Prediction for Decision Makers, handout for course AMMO-T-22, Sept. 1999.

U.S. Army Defense Ammunition Center, Chemical Hazard Prediction, handout for course AMMO-T-23, Aug. 1999.

U.S. Department of Transportation Research and Special Programs Administration, North American Emergency Response Guidebook, 2000, available at http://hazmat.dot.gov/gydebook.htm .

U.S. Environmental Protection Agency, National Contingency Plan, 40 CFR Part 300.

U.S. Environmental Protection Agency, Manual of Protective Action Guides and Protective Actions for Nuclear Incidents, EPA-400-R-92-001, May 1992.

U.S. Environmental Protection Agency National Advisory Committee on Acute Exposure Guideline Levels (AEGLs) for Sulfur Mustard (Agent HD), CAS Reg. No 505-60-2, Draft, Jan. 2000.

U.S. Nuclear Regulatory Commission, Response Technical Manual 96, NUREG/BR-0150, Vol. 1, Rev. 4, March 1996.

Umatilla Chemical Depot CAIRA Plan, 3 April 2000. 
Vogt, B.M., and Sorensen, J.H., Risk Communications and the CSEPP, ORNL-6824, Oak Ridge National Laboratory, Oak Ridge, Tennessee, Sept. 1994.

Vogt, B.M., and Sorensen, J.H., Description of Survey Data Regarding the Chemical

Repackaging Plant Accident West Helena, Arkansas, ORNL/TM-13722, Oak Ridge National Laboratory, Oak Ridge, Tennessee, March 1999, available at http://emc.ornl.gov/EMC/PDF/DescriptSurveyV3.pdf.

Warning, Evacuation and In-Place Protection Handbook, Emergency Management Division, Michigan Department of State Police, EMD PUB-304, Jan. 1994.

Warren, M., Explosion at Chevron facility starts huge fire on San Francisco Bay, Associated Press State and Local Wire, March 26, 1999.

Wernette, D., and Lerner, K., An analysis of chemical stockpile emergency preparedness program exercise results: volume 2: preliminary evaluation and analysis of CSEPP exercise database, ANL/DIS/TM-53, Vol. 2, June 1998.

Westin, S.N., Winter, S., Karlsson, E., Hin, A., and Oeseburg, F., On Modeling of the evaporation of chemical warfare agents on the ground, Journal of Hazardous Materials A63 (1998) 5-24.

Wilson, D.J., Effectiveness of Indoor Sheltering during Long Duration Toxic Gas Releases, Department of Mechanical Engineering, University of Alberta, Edmonton, Alberta, T6G 2G8.

Wilson, D.J., Stay Indoors or Evacuate to Avoid Exposure to Toxic Gas?, Emergency Preparedness Digest, Vol. 14 No. 1, January-March 1987.

Wilson, D.J., The influence of Non-Linear Human Response to Toxic Gases on the Protection Afforded by Sheltering-in-Place, presented at the Organization for Economic Cooperation and Development and the United Nations Environment Programme (OECD/UNEP) Workshop on Emergency Preparedness and Response, Boston, Massachusetts, May 7-10, 1990.

Wilson, D.J., and B. Morrison, Ordering Shelter or Evacuation During an Outdoor Toxic Gas Release Incident: the C.A.F.C. Decision Flow Chart, presented at Fire-Rescue Canada 2000, Annual Meeting of the Canadian Association of Fire Chiefs, Aug. 13-18, 2000.

Wilson, D.J., and B.W. Zelt, The Influence of Non-Linear Human Response to Toxic Gases on the Protection Afforded by Sheltering-in-Place, presented at Organization for Economic Cooperation and Development and the United Nations Environment Programme (OECD/UNEP) Workshop on Emergency Preparedness and Response, Boston, Mass., May 7-10, 1990.

Wilson, D.J., Variation of Indoor Shelter Effectiveness Caused by Air Leakage Variability of Houses in Canada and the USA, U.S. EPA/FEMA Conference on the Effective Use of In-Place Sheltering as a Potential Option to Evacuation during Chemical Release Emergencies, Emmitsburg, Maryland, 1988. 
Wilson, D.J., Accounting for Peak Concentrations in Atmospheric Dispersion for Worst Case Hazard Assessments, Department of Mechanical Engineering, University of Alberta, Edmonton, Alberta, May 1991.

Wilson, D.J., Do Leaky Buildings Provide Effective Shelter?, Proceedings of the 10th Annual Conference, Major Industrial Accidents Council of Canada, Edmonton, Alberta, 1996.

Wu, D.L., and D.W. Sloop, A Package of Transport and Diffusion Models for Biological and Toxin Agents, US Army Chemical Research, Development, and Engineering Center, CRDEC-TR-86034, June 1986.

Youngen, G., Community emergency response to nuclear power plant accidents: a selected and partially annotated bibliography. 


\section{APPENDIX 4}

\section{LIST OF ACRONYMS}

\begin{tabular}{ll} 
ACH & Air Changes per Hour \\
AEGL & Acute Exposure Guideline Level \\
ALOHA & Areal Locations of Hazardous Atmospheres \\
ANAD & Anniston Army Depot \\
ANCA & Anniston Chemical Activity \\
ANL & Argonne National Laboratory \\
ATSDR & Agency for Toxic Substances and Disease Registry \\
CAFC & Canadian Association of Fire Chiefs \\
CAI & Chemical Accident/Incident \\
CAIRA & Chemical Accident/Incident Response and Assistance \\
CDC & Centers for Disease Control \\
CFM & Cubic Feet per Minute \\
CSEPP & Chemical Stockpile Emergency Preparedness Program \\
CWA & Chemical Warfare Agent \\
D2PC & Army computer dispersion model \\
D2-Puff & Army computer dispersion model \\
DCD & Deseret Chemical Depot \\
DOD & Department of Defense \\
DOE & Department of Energy \\
DOT & Department of Transportation \\
EAS & Emergency Alert System \\
EMA & Emergency Management Agency \\
EMIS & Emergency Management Information System \\
EOC & Emergency Operations Center \\
EPA & Environmental Protection Agency \\
FEMA & Federal Emergency Management Agency \\
FEMIS & Federal Emergency Management Information System \\
GAPCAP & Generation of Assessment Patterns for Clouds of Airborne Particles \\
GB & Non-persistent nerve agent \\
HAZMAT & Hazardous Materials \\
HD & Mustard agent \\
HHS & Department of Health and Human Services \\
HVAC & Heating, Ventilation, and Air Conditioning \\
ICAM & Individual Chemical Agent Monitor \\
IEM & Innovative Emergency Management \\
IPT & Integrated Process Team \\
IRF & Initial Response Force \\
IRZ & Immediate Response Zone \\
MCE & Maximum Credible Event \\
MOA & Memorandum of Agreement \\
NCD & Newport Chemical Depot \\
& \\
\hline
\end{tabular}




$\begin{array}{ll}\text { NICS } & \text { National Institute for Chemical Studies } \\ \text { NRC } & \text { Nuclear Regulatory Commission } \\ \text { ORNL } & \text { Oak Ridge National Laboratory } \\ \text { OSC } & \text { On-Scene Coordinator } \\ \text { OSHA } & \text { Occupational Safety and Health Agency } \\ \text { PAD } & \text { Protective Action Decision } \\ \text { PADRE } & \text { Protective Action Dosage Reduction Estimator } \\ \text { PAECE } & \text { Protective Action Evaluator for Chemical Emergencies } \\ \text { PAO } & \text { Public Affairs Officer } \\ \text { PAR } & \text { Protective Action Recommendation } \\ \text { PARDOS } & \text { Partial Dosage (computer program) } \\ \text { PIO } & \text { Public Information Officer } \\ \text { RSPA } & \text { Research and Special Programs Administration } \\ \text { RTAP } & \text { Real-Time Analytical Platform } \\ \text { SIMCELL } & \text { Simulation Cell } \\ \text { SIP } & \text { Shelter-in-Place (Refers primarily to normal, expedient, and enhanced } \\ & \text { shelter in this report) } \\ \text { TWA } & \text { Time Weighted Average } \\ \text { UMCD } & \text { Umatilla Chemical Depot } \\ \text { USADAC } & \text { US Army Defense Ammunition Center } \\ \text { USASBCCOM } & \text { US Army Soldier and Biological/Chemical Command } \\ \text { VX } & \text { Persistent nerve agent }\end{array}$

